University of Nebraska - Lincoln

DigitalCommons@University of Nebraska - Lincoln

September 2007

\title{
Effect of Hydrofluoric Acid in Oxidizing Acid Mixtures on the Hydroxylation of Silicon Surface
}

\author{
Sanjukta Guhathakurta \\ University of Nebraska - Lincoln \\ Anuradha Subramanian \\ Department of chemical Engineering,University of Nebraska Lincoln., asubramanian2@unl.edu
}

Follow this and additional works at: https://digitalcommons.unl.edu/cbmesubramanian

Part of the Chemical Engineering Commons

Guhathakurta, Sanjukta and Subramanian, Anuradha, "Effect of Hydrofluoric Acid in Oxidizing Acid Mixtures on the Hydroxylation of Silicon Surface" (2007). Anuradha Subramanian Publications. 2. https://digitalcommons.unl.edu/cbmesubramanian/2

This Article is brought to you for free and open access by the Chemical and Biomolecular Research Papers -- Faculty Authors Series at DigitalCommons@University of Nebraska - Lincoln. It has been accepted for inclusion in Anuradha Subramanian Publications by an authorized administrator of DigitalCommons@University of Nebraska - Lincoln. 


\title{
Effect of Hydrofluoric Acid in Oxidizing Acid Mixtures on the Hydroxylation of Silicon Surface
}

\author{
Sanjukta Guhathakurta and Anuradha Subramanian ${ }^{\mathrm{z}}$
}

Department of Chemical and Biomolecular Engineering, University of Nebraska Lincoln, Lincoln, Nebraska 68588, USA

\begin{abstract}
Silicon (100) wafers, predipped in 1:20 (v/v) HF water, were treated separately with four different acid mixtures, viz., $\mathrm{HNO}_{3}$, $\mathrm{H}_{2} \mathrm{SO}_{4}-\mathrm{H}_{2} \mathrm{O}_{2}, \mathrm{HNO}_{3}-\mathrm{HF}$, and $\mathrm{H}_{2} \mathrm{SO}_{4}-\mathrm{H}_{2} \mathrm{O}_{2}-\mathrm{HF}$, for different time durations. Subsequent vigorous rinsing with deionized water rendered the wafer surfaces with hydroxyl termination. Synthesized surfaces were characterized by diffuse-reflectance infrared Fourier transform spectroscopy (DRIFTS), ellipsometry, contact angle and atomic force microscopy. Surfaces treated with $\mathrm{HNO}_{3}$ and $\mathrm{H}_{2} \mathrm{SO}_{4}-\mathrm{H}_{2} \mathrm{O}_{2}$ showed increasing hydrophilicity at room temperature due to the formation of silanol $(-\mathrm{SiOH})$ terminated chemical oxides, with continuous oxide growth. An increase in hydrophilicity was observed during the first 15 min of treatment with $\mathrm{HNO}_{3}-\mathrm{HF}$ and $\mathrm{H}_{2} \mathrm{SO}_{4}-\mathrm{H}_{2} \mathrm{O}_{2}-\mathrm{HF}$ acid mixtures, causing a decrease in the hydrophilic character with longer incubation times DRIFTS analysis confirmed the addition of HF in the oxidizing acid mixture controls chemical oxide proliferation, through creating a surface with mixed $-\mathrm{SiOH}$ and silicon hydride $\left(-\mathrm{SiH}_{x}\right)$ termination. Prolonged incubation in acidic mixtures containing $\mathrm{HF}$ resulted in a logarithmic increase of $-\mathrm{SiH}_{x}$ coverage, rendering the surface hydrophobic. Incubation for 15 minutes in each of the four acid mixture systems generated surfaces with comparable hydrophilicity, controlled oxide growth and reduced surface roughness.
\end{abstract}

(C) 2007 The Electrochemical Society. [DOI: 10.1149/1.2779951] All rights reserved.

Manuscript submitted April 20, 2007; revised manuscript received July 25, 2007. Available electronically September $24,2007$.

Modification of solid surfaces to enable the covalent immobilization of biomolecules has become an important step in the generation of surfaces with tailored binding properties. ${ }^{1}$ Surfaces based on silicon $(\mathrm{Si})$ have found applications in micro- and opto-electronic devices, memory chips, and sensitive biological sensors. ${ }^{2}$ Recently, silicon based surfaces have shown promising results in biomaterial applications due to their favorable surface modification properties to anchor biomolecules. ${ }^{3}$ A general methodology for the attachment of biologically relevant molecules to silicon surface demands surface functionalization through hydroxylation and termination of surface with silanes (Fig. 1).

A bare silicon wafer is covered with a layer of native oxide $\left(\mathrm{SiO}_{2-x}\right)$, the nature of which is different from the wet chemically grown oxide. ${ }^{4}$ Native oxide has siloxane rings which are very stable against hydrolysis, therefore are hydrophobic in nature. Molecular properties of silicon are strongly dependent on the nature of the surface functional groups. The unsaturated surface valencies (surface dangling bond) are satisfied by the surface hydroxyl functionalities (-SiOH groups) through different wet-chemical treatments. This is the first step in the attachment of biologically relevant molecules to silicon surface (see Fig. 1).

Various wet-chemical methods have been developed in the semiconductor industry to clean wafer surfaces with various functional group terminations. ${ }^{5-7}$ The acid treatment oxidizes the contaminants present on the surface along with surface oxidation, leading to the formation of a wet-chemical oxide $\left(\mathrm{SiO}_{2-x}\right)$ following the logarithmic growth law and renders the surface hydrophilic after water rinsing, with the installation of $\mathrm{SiOH}$ groups. ${ }^{8}$

Along with the growth of wet-chemically grown chemical oxide on a semiconductor grade silicon wafer, contamination becomes a critical issue as metal ions and particulate get adsorbed easily on hydrophilic, wet-chemically grown oxide surface. ${ }^{9} \mathrm{H}_{2} \mathrm{SO}_{4}-\mathrm{H}_{2} \mathrm{O}_{2}$ (sulfuric-hydrogen peroxide acid mixtures, known as $\mathrm{SPM}^{10}$ ) is well known to produce uniform $\mathrm{SiOH}$ on the surface of silicon nanoparticles. ${ }^{11}$ But $\mathrm{H}_{2} \mathrm{SO}_{4}$ is a viscous acid and sulfur removal often becomes difficult by routine water rinsing which results in a sticky, contamination prone surface. ${ }^{10}$ Washing with mild alkaline solution (e.g., sodium hydroxide, $\mathrm{NaOH}$ ) is not advisable because of adsorption of metal ions, their aqua-, and hydroxo complexes on to the silica surface. ${ }^{4}$ Nitric acid treatment is recommended by the American Society for Testing and Materials (ASTM) for standard

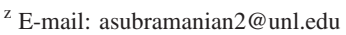

surface treatment of medical devices (ASTM-F86). ${ }^{12} \mathrm{HNO}_{3}$ is less viscous than $\mathrm{H}_{2} \mathrm{SO}_{4}$ and easily rinsable, but it is known to produce thicker oxide than SPM because of its strong oxidizing nature. ${ }^{10}$

Recently, extensive X-ray photoelectron spectroscopy (XPS) study has shown that the inclusion of a minute amount of HF with SPM during the wet-cleaning step increases rinsing efficiency by reducing sulfur $(\mathrm{S})$ contamination and controlling growth of the oxide layer. ${ }^{13}$ It has been hypothesized that the inclusion of HF during the oxidation step renders a surface hydrophobic as most surface dangling bonds are occupied with fluorine $(\mathrm{Si}-\mathrm{F})$ and reduces $\mathrm{S}$ adsorption on the surface. Followed by aqueous rinsing, passivation by fluoride $\left(\mathrm{F}^{-}\right)$can be potentially removed to render the surface hydrophilic via the exchange of fluorine with $\mathrm{OH}^{-}$groups. ${ }^{14,15} \mathrm{Re}-$ searchers have been able to reduce $\mathrm{S}$ contamination on surfaces up to few atomic percent with controlled oxide growth. ${ }^{10}$ The addition of a low concentration of $\mathrm{HF}$ into the $\mathrm{HNO}_{3}$ solution (known as $\mathrm{SE}$, slight etch) controls oxide growth by competitive oxidation and etching together. ${ }^{10,16}$ Further, nonrinsed surfaces prepared with SE were blow-dried easily, whereas sulfuric-peroxide-fluoride mixture (SPFM) treated surfaces were difficult to dry. ${ }^{10} \mathrm{An}$ atomic force microscopy (AFM) study did not show any noticeable increase of micro roughness with the addition of $\mathrm{HF}$ in parts per million levels (ppm).

The goal of our research is to generate Si-based surfaces with protein binding capabilities that can be further used in biosensor or
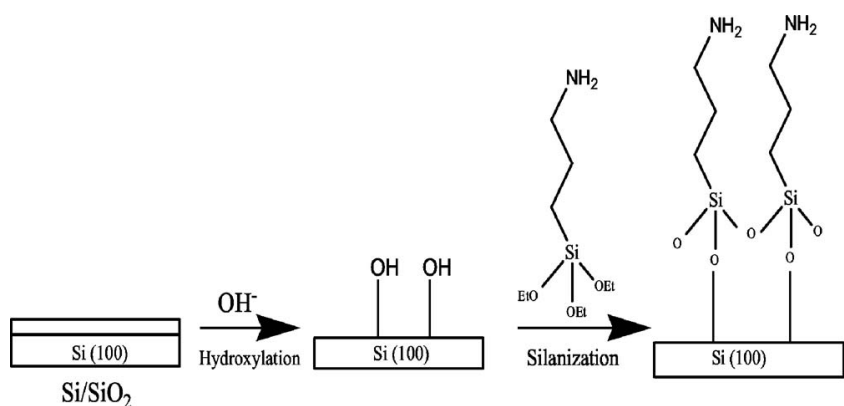

Figure 1. Schematic representation of surface modification of p-type silicon (100) wafer for silanization. The first step is hydroxylation using different oxidizing and oxide-etching mixture, followed by water rinsing. Generated $\mathrm{SiOH}$ group on $\mathrm{Si}(100)$ is then made to react with $\gamma$-aminopropyltriethoxysilane (APTES) to get silane modified surface. This functionalization can be used for different purposes further. 
biomaterial applications. Biocompatibility of a surface is dependent on its surface chemistry, microstructure, and the in vitro interaction with surface oxide. ${ }^{17}$ It is important to control surface chemistry of an ideally flat, unreconstructed, semiconductor grade silicon (100) biomaterial to get improved quality of surface oxide with good amount of hydrophilicity, metal-particulate contamination free surface with minimum microroughness. Longer contact time in oxidizing, oxidizing-etching mixture with silicon surface may result in more or less hydrophilicity on the surface. In our present study, we have investigated the nature of the surface termination and effected surface properties: hydrophilicity, thickness and microroughness depending on the different reaction time and methods of treatment used. The underlying hypothesis is that surfaces, pre-exposed to HF and then subjected to oxidizing-etching mixture will result in greater hydrophilicity, a desired feature for surfaces in biomaterial application. In our study, we have investigated four treatments $\left(\mathrm{HNO}_{3}\right.$, $\mathrm{H}_{2} \mathrm{SO}_{4}-\mathrm{H}_{2} \mathrm{O}_{2}, \mathrm{HNO}_{3}-\mathrm{HF}$, and $\mathrm{H}_{2} \mathrm{SO}_{4}-\mathrm{H}_{2} \mathrm{O}_{2}-\mathrm{HF}$ ) to evaluate the hydrophilic nature of the surface depending upon the contact time with silicon wafer and further characterized the resultant surface with diffuse-reflectance infrared Fourier transform (DRIFT) spectra, ellipsometry, contact angle analysis, and AFM.

\section{Experimental}

Materials. - Silicon (100) wafers, p-type, 2 in. diam., one side polished were purchased with resistivity $<0.01$. Hydrofluoric acid (ACS grade, 48-51\%), nitric acid (NF grade, 20-70\%), sulfuric acid (ACS plus, 90-98\%), hydrogen peroxide (ACS reagent, without stabilizer, 30\% in water), ethanol (200 proof), diiodomethane $(99 \%)$, $\alpha$-bromonaphthalene (97\%), ethylene glycol (99.8\% anhydrous), glycerol $(99 \%)$ were used throughout the experiments and used as received. A Teflon beaker was used for HF treatments. Deionized water (DI water) with resistivity $18 \mathrm{M} \Omega \mathrm{cm}$ was used throughout the reactions.

Sample preparation.- Silicon wafers were cut into pieces (1 $\times 1 \mathrm{~cm})$. Prior to acid treatments, wafers were rinsed and sonicated with ethanol (three times) followed by DI water rinsing (three times) for 2 min. Experiments with HF were carried out in Teflon beakers. Wafers were dipped into 1:20 v/v HF water for 2 min and rinsed with DI water vigorously for $5 \mathrm{~min}$. Wafers were then soaked in $\mathrm{HNO}_{3}, 4: 1 \mathrm{v} / \mathrm{v}$ mixture $\mathrm{H}_{2} \mathrm{SO}_{4}-\mathrm{H}_{2} \mathrm{O}_{2}$, mixture of $\mathrm{HNO}_{3}$ and $500 \mathrm{ppm} \mathrm{HF}$, mixture of $4: 1 \mathrm{v} / \mathrm{v}$ mixture of $\mathrm{H}_{2} \mathrm{SO}_{4}, \mathrm{H}_{2} \mathrm{O}_{2}$, and $100 \mathrm{ppm}$ HF followed by the methods discussed elsewhere ${ }^{\mathrm{YO}}$ and allowed 5, 15, 30, 45, and 60 min for reaction. In $\mathrm{HNO}_{3}$ and SE treatment, $80^{\circ} \mathrm{C}$ temperatures were maintained whereas SPM and SPFM mixtures were highly exothermic $\left(\sim 120^{\circ} \mathrm{C}\right)$. After rinsing with DI water for 15 min., surfaces were dried under nitrogen flow and stored in vacuum desiccators. Both concentrations of HF ( $500 \mathrm{ppm}$ of HF in SE and $100 \mathrm{ppm}$ of HF in SPFM) were selected to achieve higher hydroxyl content $(\mathrm{SiOH})$ on $\mathrm{Si}(100)$ surface after water rinsing with reasonable low oxide etching rate and low surface microroughness. ${ }^{10}$ In a separate experiment, wafers were directly exposed to all four oxidizing acid mixtures with no prior HF dipping.

Surface characterization. - The hydroxylated silicon surfaces were characterized by DRIFTS, ellipsometry, contact angle analysis, and AFM techniques.

DRIFTS. - DRIFT spectra were collected on a Nicollet 20SXB operating in Kubelka-Munk mode at a $4 \mathrm{~cm}^{-1}$ spectral resolution with 512 scans, with nonabsorbing potassium bromide $(\mathrm{KBr})$ as background. Bare, unprocessed silicon wafer was considered as standard. The sample was mounted in a dry air purged sample chamber to remove all atmospheric moisture on the substrate. The scan number was kept high to reduce noise in the spectra, created by reflection from the surface. All spectra were baseline corrected and automatically smoothened using Omnic software. The DRIFT spectra were five times weaker than the attenuated total reflectance
(ATR) ones, but the positions of the main bands were consistent with literature. ${ }^{18}$ Because of the weakness of DRIFT spectra, it was difficult to avoid the appearance of false bands from the $\mathrm{CO}_{2}$ and hydrocarbons inclusions in the detector window. Scans were taken immediately after sample preparation. Peakfit V4.11 software was used to calculate the area under certain spectrum region and deconvolute spectra where local maxima-minima were not clearly visible.

Ellipsometry.- The thickness of the surface film was measured using HS-190, variable-angle spectroscopic ellipsometry (VASE), operating in the UV-visible region. Spectroscopic ellipsometry measurements were done immediately after sample preparation. All measurements were done in air and the hydroxylated surface was modeled using the Cauchy model. Formation of $\mathrm{SiO}_{2-x}$ could not be avoided when measurement was done in air. Each reported value represents the average value of at least three separate thickness values from three different sets of experiments.

Contact angle.- Advancing contact angle measurement was performed following sessile drop method with OCA 15, SCA 20 Data Physics Instrument GmbH. DI water, ethylene glycol, glycerol, diiodomethane, and $\alpha$-bromonaphthalene were used to perform these tests. The size and volume of the drops were kept constant $1 \mu \mathrm{L}$ with flow rate of $0.1 \mu \mathrm{L} / \mathrm{s}$ ). Contact angle measurements were done after an average $6-8 \mathrm{~h}$ of sample preparation to get measurable data on highly hydrophilic surfaces (to prevent droplet spreading due to high hydrophilicity). To avoid spreading of the drops and droplet shape variation, contact angle values were recorded within 15-20 s after placing the drop. Each reported value is the average of at least three drops on different areas of a wafer. Repeated measurements from three different sets of reactions show all contact angle values with $\pm 5^{\circ}$ variation. All measurements were conducted in air and at a temperature of $23^{\circ} \mathrm{C}$.

Atomic force microscopy.- Surface topography was obtained with automated AFM, The Digital Instruments Nanoscope IIIa Dimension 3100 SPM, operating in tapping mode. A silicon tip with a cantilever length of $\sim 125 \mu \mathrm{m}$, width $\sim 30 \mu \mathrm{m}$, thickness $\sim 3 \mu \mathrm{m}$ was used and a characteristic frequency of $300-330 \mathrm{kHz}$ was employed for capturing the image. All images were taken in air atmosphere with 512 scans. All three-dimensional (3D) images of the wafer surfaces were obtained from $2 \times 2 \mu \mathrm{m}$ wafer regions. Root mean square (rms) (in $\mathrm{nm}$ ) gives the value of roughness, created by different methods

$$
R_{\mathrm{rms}}=\sqrt{\left[\sum\left(z_{n}-\dot{z}\right) 2 /(N-1)\right]}
$$

$R_{\text {rms }}$ (root mean square deviation of surface roughness) values can be calculated using the above equation where $z_{n}(\mathrm{~nm})$ is the height of a random location on the scanned surface, $\dot{z}$ is the mean height $(\mathrm{nm})$ of all measured heights, and $N$ is the sample size (i.e., number of height values).

\section{Results and Discussion}

Diffuse-reflectance infrared Fourier transform spectroscopy analysis. - Treatment of surfaces with HF prior to incubation in oxidizing/oxide-etching mixtures, typically results in a surface with hydrogen termination [silicon dihydride, $\mathrm{SiH}_{2}$ mainly for $\mathrm{Si}(100)] .{ }^{17,19}$ The wet chemical etching-oxidation method of the hydrogen terminated wafer initiates the exchange reaction of surface $\mathrm{Si}-\mathrm{H}$ with $\mathrm{Si}-\mathrm{OH}$. The surface condition of $\mathrm{Si}(100)$ depends on the $\mathrm{pH}$ used (Table IV). Figures 2-5 show the DRIFT spectra of all the surfaces treated with $\mathrm{HNO}_{3}, \mathrm{H}_{2} \mathrm{SO}_{4}-\mathrm{H}_{2} \mathrm{O}_{2}, \mathrm{HNO}_{3}-\mathrm{HF}$, and $\mathrm{H}_{2} \mathrm{SO}_{4}-\mathrm{H}_{2} \mathrm{O}_{2}-\mathrm{HF}$, respectively, in the region of $3500-4000 \mathrm{~cm}^{-1}$. Strong absorptions were observed at $3718-3720 \mathrm{~cm}^{-1}$ in all spectra obtained which corresponded to the $-\mathrm{SiO}-\mathrm{H}$ stretching $(v)$ vibrations. ${ }^{20}$ A broader peak at $3720 \mathrm{~cm}^{-1}$ indicates broader distribution of $-\mathrm{Si}-\mathrm{OH}$ groups and a well-ordered surface structure. In all spectra, a stretching in the $1200-1280 \mathrm{~cm}^{-1}$ region was observed (not shown), which corresponded to an asymmetric $\mathrm{Si}-\mathrm{O}-\mathrm{Si}$ stretch- 


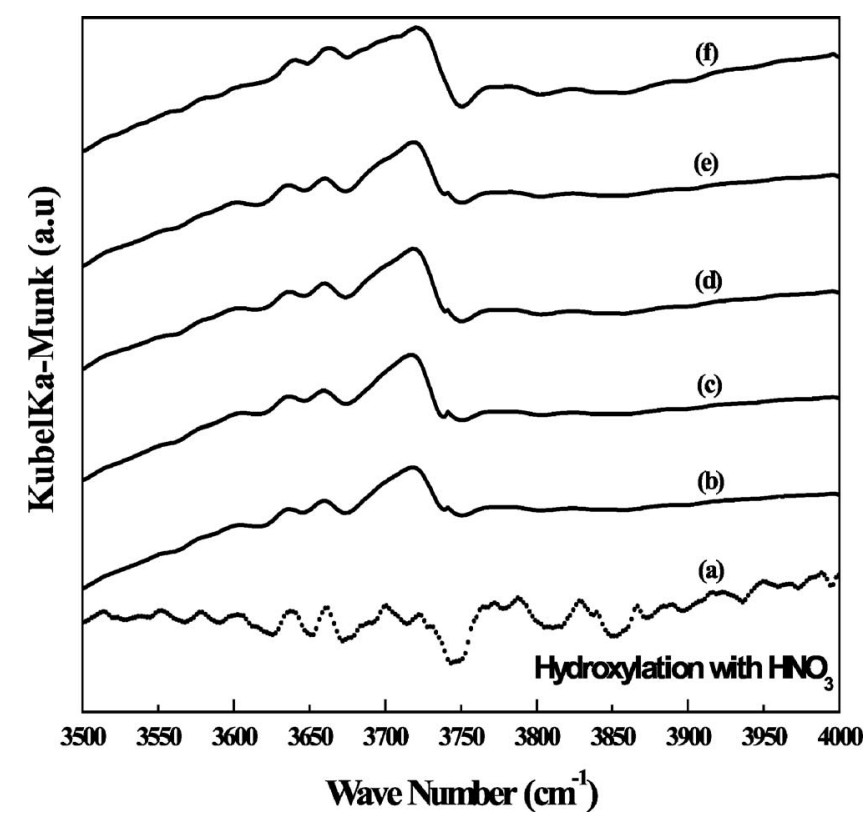

Figure 2. DRIFT spectra in the spectral region of $3500-4000 \mathrm{~cm}^{-1}$, for the $\mathrm{Si}(100)$ surfaces treated with $20-70 \% \mathrm{HNO}_{3}$ and temperature maintained at $80^{\circ} \mathrm{C}$ for (b) $5 \mathrm{~min}$, (c) $15 \mathrm{~min}$, (d) $30 \mathrm{~min}$, (e) $45 \mathrm{~min}$, and (f) $60 \mathrm{~min} . \mathrm{pH}$ of the acid varied between 1.4 and 1.5 . Stretch at $3718 \mathrm{~cm}^{-1}$ corresponds to $\mathrm{SiOH}$. All spectra were compared with the reference unmodified blank $\mathrm{Si}(100)$ wafer [shown in (a)].

ing $\left(\nu_{\mathrm{Si}-\mathrm{O}-\mathrm{Si}}\right)^{21}$ When surfaces were treated with SPFM and SE, little humps in the region of $2000-2300 \mathrm{~cm}^{-1}$ were observed. Figures $6 \mathrm{~A}$ and $7 \mathrm{~A}$ show absorption band in the $2000-2300 \mathrm{~cm}^{-1}$ region due to the absorption from $\mathrm{SiH}_{x}$ groups. ${ }^{11,19,21-23}$ The typical

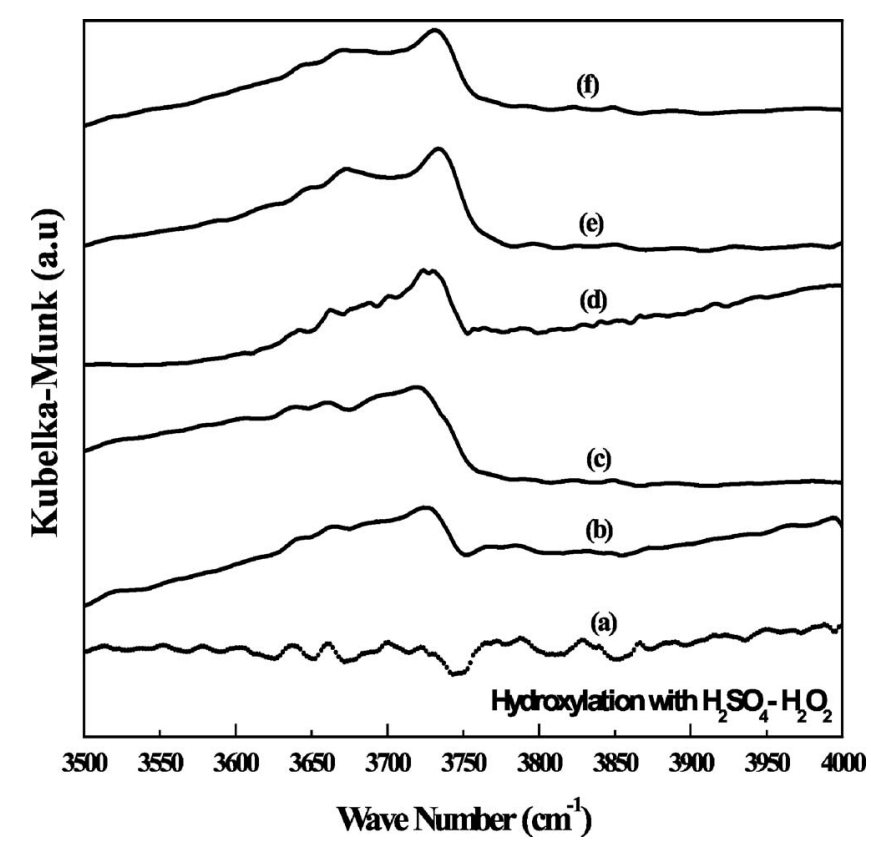

Figure 3. DRIFT spectra in the spectral region of $3500-4000 \mathrm{~cm}^{-1}$, for the $\mathrm{Si}(100)$ surfaces treated with $4: 1 \mathrm{v} / \mathrm{v}$ mixture of $90-98 \% \mathrm{H}_{2} \mathrm{SO}_{4}$ and $30-$ $50 \% \mathrm{H}_{2} \mathrm{O}_{2}$ for (b) $5 \mathrm{~min}$, (c) $15 \mathrm{~min}$, (d) $30 \mathrm{~min}$, (e) $45 \mathrm{~min}$, and (f) $60 \mathrm{~min}$. Exothermic reaction mixtures were maintained $\sim 120^{\circ} \mathrm{C}$. $\mathrm{pH}$ of the acid mixture varied between 1.2 and 1.5 . Stretch at $3718 \mathrm{~cm}^{-1}$ corresponds to $\mathrm{SiOH}$. All spectra were compared with the reference unmodified blank $\mathrm{Si}(100)$ wafer [shown in (a)].

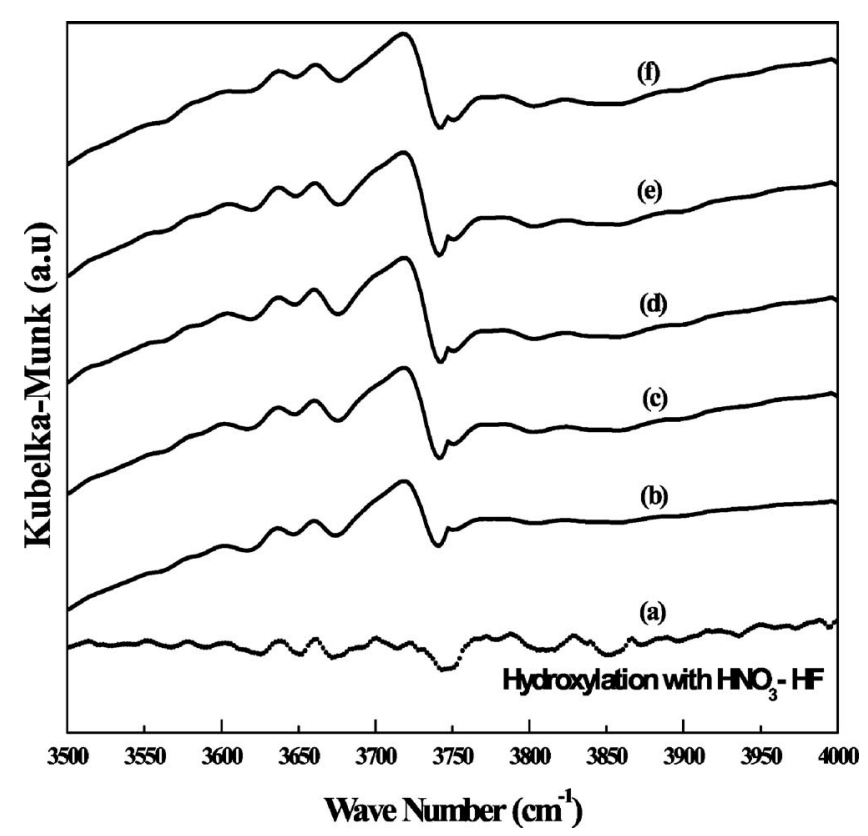

Figure 4. DRIFT spectra in the spectral region of $3500-4000 \mathrm{~cm}^{-1}$, for the $\mathrm{Si}(100)$ surfaces treated with oxide-etching mixture of $20-70 \% \mathrm{HNO}_{3}$ and $500 \mathrm{ppm}$ of $48-51 \% \mathrm{HF}$ and temperature maintained at $80^{\circ} \mathrm{C}$ for (b) $5 \mathrm{~min}$, (c) $15 \mathrm{~min}$, (d) $30 \mathrm{~min}$, (e) $45 \mathrm{~min}$, and (f) $60 \mathrm{~min} . \mathrm{pH}$ of the acid mixture varied between 0.2 and 0.4 . Stretch at $3720 \mathrm{~cm}^{-1}$ corresponds to $\mathrm{SiOH}$. All spectra were compared with the reference unmodified blank $\mathrm{Si}(100)$ wafer [shown in (a)].

tripartite structure was not visible in the weak DRIFT spectra. All spectra were further deconvoluted in the region of 2000-2300 cm-1 and only surfaces for 5 min treatments are shown in Fig. 6B and 7B.

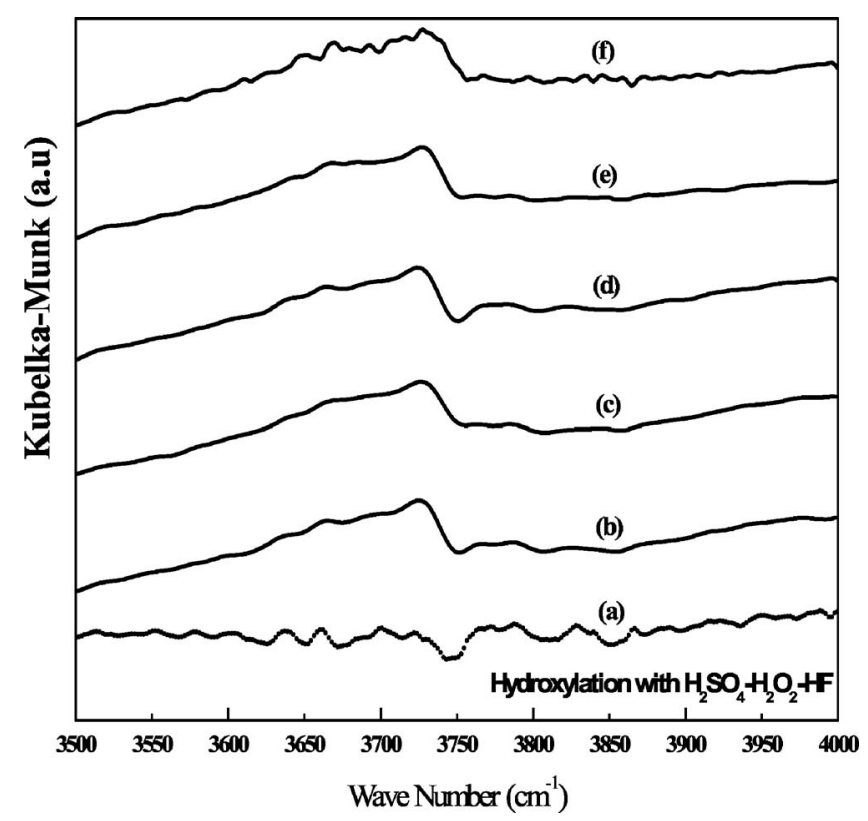

Figure 5. DRIFT spectra in the spectral region of $3500-4000 \mathrm{~cm}^{-1}$, for the $\mathrm{Si}(100)$ surfaces treated with $4: 1 \mathrm{v} / \mathrm{v}$ mixture of $90-98 \% \mathrm{H}_{2} \mathrm{SO}_{4}, 30-50 \%$ $\mathrm{H}_{2} \mathrm{O}_{2}$ and $100 \mathrm{ppm}$ of $48-51 \% \mathrm{HF}$ for (b) $5 \mathrm{~min}$, (c) $15 \mathrm{~min}$, (d) $30 \mathrm{~min}$, (e) $45 \mathrm{~min}$, and (f) $60 \mathrm{~min}$. Exothermic reaction mixtures were maintained at $\sim 120^{\circ} \mathrm{C}$. $\mathrm{pH}$ of the acid mixture varied between 0.1 and 0.4 . Stretch at $3720 \mathrm{~cm}^{-1}$ corresponds to $\mathrm{SiOH}$. All spectra were compared with the reference unmodified blank $\mathrm{Si}(100)$ wafer [shown in (a)]. 


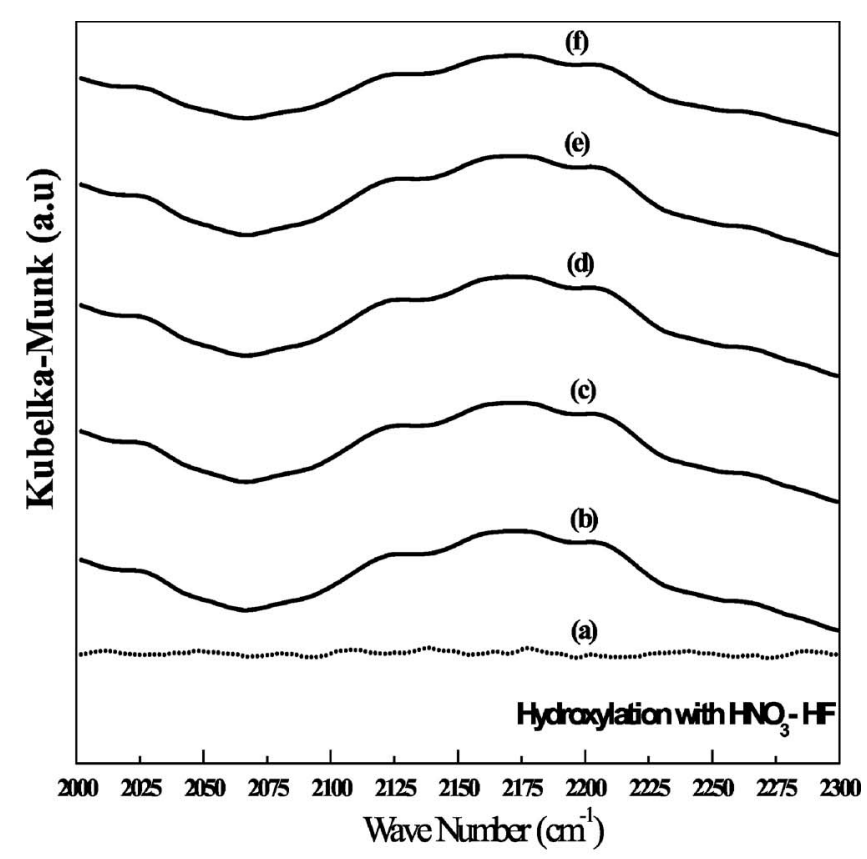

(A)

(B)

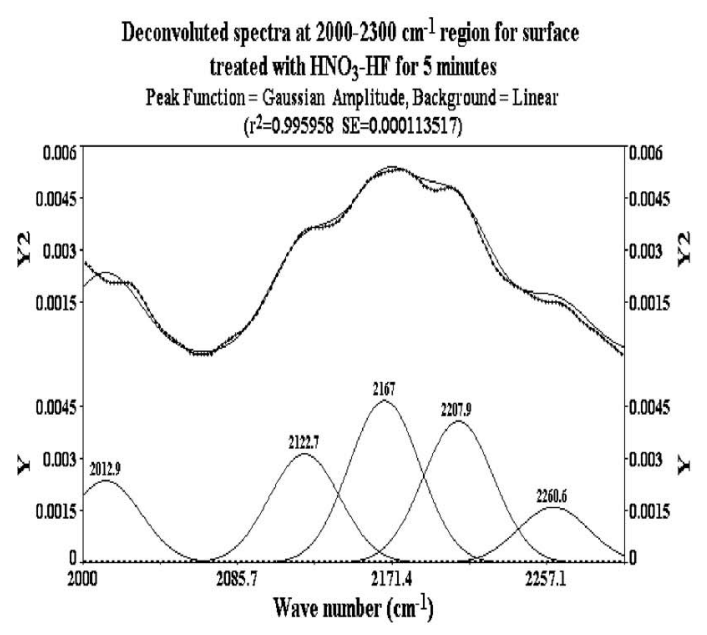

Figure 6. (A) DRIFT spectra in the spectral region of $2000-2300 \mathrm{~cm}^{-1}$ (responsible for $\mathrm{Si}-\mathrm{H}_{x}$ vibration), for the $\mathrm{Si}(100)$ surfaces treated with oxide etching mixture of $20-70 \% \mathrm{HNO}_{3}$ and $500 \mathrm{ppm}$ of $48-51 \% \mathrm{HF}$ at $80^{\circ} \mathrm{C}$ for (b) $5 \mathrm{~min}$, (c) $15 \mathrm{~min}$, (d) $30 \mathrm{~min}$, (e) $45 \mathrm{~min}$, and (f) $60 \mathrm{~min} . \mathrm{pH}$ of the acid mixture varied between 0.2 and 0.4 . Stretch at $3720 \mathrm{~cm}^{-1}$ corresponds to $\mathrm{SiOH}$. All spectra were compared with the reference unmodified blank $\mathrm{Si}(100)$ wafer [shown in (a)]. (B) Deconvolution of the peaks in the spectral region of 2000-2300 $\mathrm{cm}^{-1}$ for the surface treated with oxide-etching mixture of $20-70 \% \mathrm{HNO}_{3}$ and $500 \mathrm{ppm}$ of $48-51 \% \mathrm{HF}$ at $80^{\circ} \mathrm{C}$ for $5 \mathrm{~min}$ using software Peakfit v4.12. Y denotes deconvolved data whereas Y2 denotes raw data with sum curve. Deconvolution shows tripartite structure of $\mathrm{SiH}_{x}$.

Absorption at 2122, 2167, and $2207 \mathrm{~cm}^{-1}$ (Fig. 6B and 7B) are mainly from silicon dihydride $\left(v_{\mathrm{Si}-\mathrm{H}_{2}}\right){ }^{19}$ Absorptions at $2260 \mathrm{~cm}^{-1}$ (Fig. 6B and 7B) $\left(v_{\mathrm{Si}-\mathrm{H}}\right)$ correspond to the stretching mode of oxygen back bonded silicon monohydride $(\mathrm{O}-\mathrm{SiH}){ }^{21,22}$

It is well known that the integrated absorbance in the Fourier transform infrared is proportional to the surface density of molecules. ${ }^{18}$ Integrated absorbance between 980 and $1300 \mathrm{~cm}^{-1}$ from $\mathrm{Si}-\mathrm{O}-\mathrm{Si}$ remains stable during chemical treatments and can be used as an internal reference. Hence the amount of $\mathrm{Si}-\mathrm{H}_{x}$ was estimated by the integrated absorbance ratio of $\mathrm{SiH}_{x}\left(2000-2300 \mathrm{~cm}^{-1}\right)$

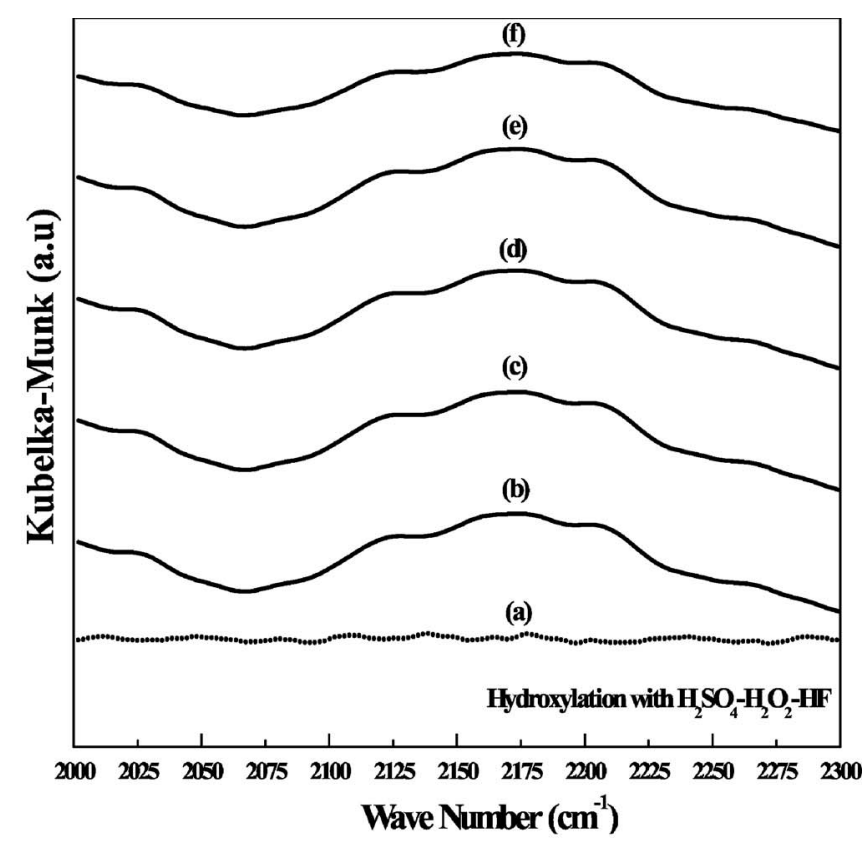

(A)

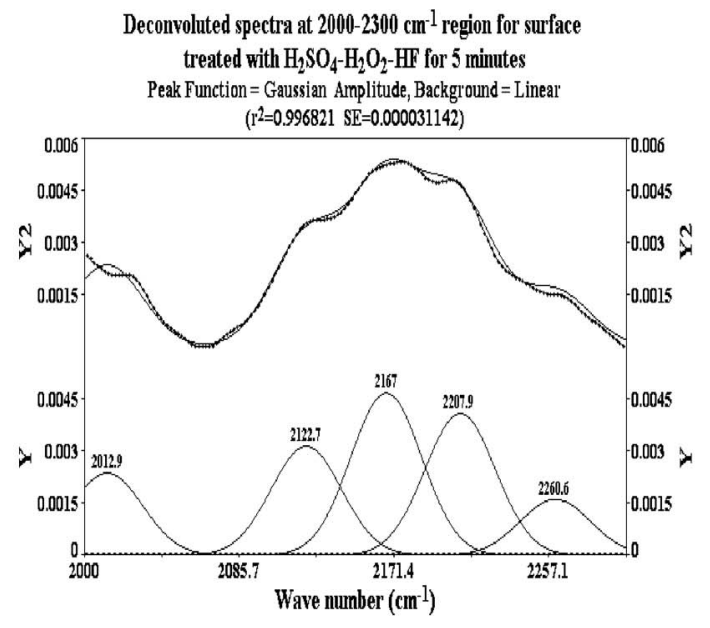

Figure 7. (A) DRIFT spectra in the spectral region of $2000-2300 \mathrm{~cm}^{-1}$ (responsible for $\mathrm{Si}-\mathrm{H}_{x}$ vibration), for the $\mathrm{Si}(100)$ surfaces treated with $4: 1 \mathrm{v} / \mathrm{v}$ mixture of $90-98 \% \mathrm{H}_{2} \mathrm{SO}_{4}, 30-50 \% \mathrm{H}_{2} \mathrm{O}_{2}$ and $100 \mathrm{ppm}$ of $48-51 \%$ HF for (b) $5 \mathrm{~min}$, (c) $15 \mathrm{~min}$, (d) $30 \mathrm{~min}$, (e) $45 \mathrm{~min}$, and (f) $60 \mathrm{~min}$. $\mathrm{pH}$ of the acid mixture varied between 0.2 and 0.4 . Stretch at $3720 \mathrm{~cm}^{-1}$ corresponds to $\mathrm{SiOH}$. All spectra were compared with the reference unmodified blank $\mathrm{Si}(100)$ wafer [shown in (a)]. (B) Deconvolution of the peaks in the spectral region of 2000-2300 $\mathrm{cm}^{-1}$ for the surface treated with $4: 1 \mathrm{v} / \mathrm{v}$ mixture of $90-98 \% \mathrm{H}_{2} \mathrm{SO}_{4}, 30-50 \% \mathrm{H}_{2} \mathrm{O}_{2}$ and $100 \mathrm{ppm}$ of $48-51 \% \mathrm{HF} 5 \mathrm{~min}$ using software Peakfit v4.12. Y denotes deconvolved data whereas Y2 denotes raw data with sum curve. Deconvolution shows two humps responsible for $\mathrm{SiH}_{x}$.

to $\mathrm{Si}-\mathrm{O}-\mathrm{Si}\left(980-1300 \mathrm{~cm}^{-1}\right)$ as shown in Fig. 8. A logarithmic trend was visible in both the surfaces treated with $\mathrm{HNO}_{3}-\mathrm{HF}$ and $\mathrm{H}_{2} \mathrm{SO}_{4}-\mathrm{H}_{2} \mathrm{O}_{2}-\mathrm{HF}$; however, both the treatment protocols yielded surfaces with a continuous increase of $\mathrm{SiH}_{x}$ coverage making the surface hydrophobic with a lapse of time.

Ellipsometry analysis and determination of surface hydroxyl group density.-Figure 9 shows the change of thickness of hydroxyl terminated chemical oxide layer on silicon wafer surface, as measured by VASE and modeled by Cauchy layer approximation. 


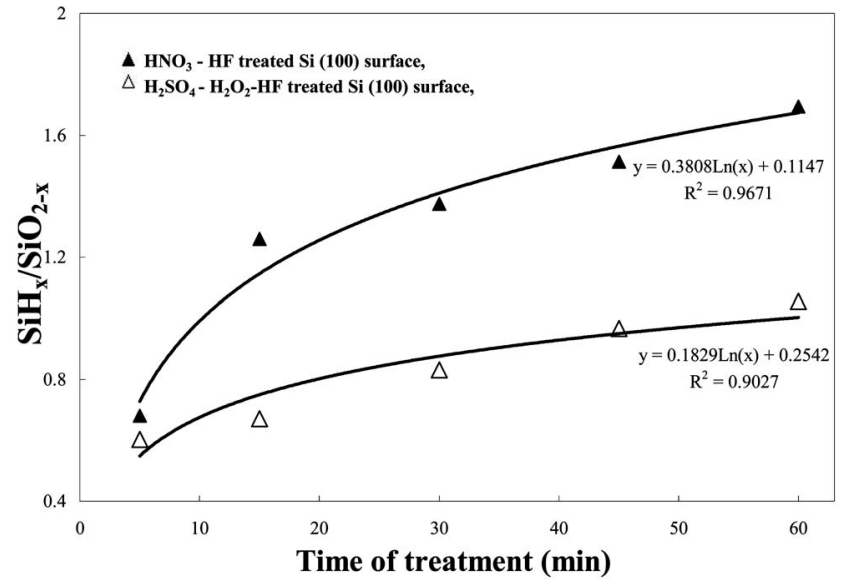

Figure 8. Change of intensity ratio due to $\mathrm{Si}-\mathrm{H}_{x}$ vibration bands (in 2000-2300 $\mathrm{cm}^{-1}$ wave number region) for surfaces (predipped in 1:20 v/v $\mathrm{HF}$ solution) treated with (a) 20-70\% $\mathrm{HNO}_{3}$ and $500 \mathrm{ppm} \mathrm{HF}$, (b) $4: 1 \mathrm{v} / \mathrm{v}$ mixture of $90-98 \% \mathrm{H}_{2} \mathrm{SO}_{4}, 30-50 \% \mathrm{H}_{2} \mathrm{O}_{2}$ and $100 \mathrm{ppm} \mathrm{HF}$ for different contact times, followed by DI water rinsing and drying in nitrogen atmosphere. Si-O vibrations (in the range of $980-1300 \mathrm{~cm}^{-1}$ ) were considered as internal standard for comparing all DRIFT spectra. Both the treatments show continuous increase of $\mathrm{SiH}_{x}$ coverage and finally reach to saturation.

The thickness of bare, unmodified wafer was also measured and modeled considering the native oxide layer and from corresponding refractive indices reported in literature. The thickness, observed over time, increased for surfaces treated with $\mathrm{HNO}_{3}$ and SPM. Change of thickness was more for $\mathrm{HNO}_{3}$ compared to SPM because of its strong oxidizing property. For surface treated with SPFM and SE, there was not much variation in thickness. This indicated a con-

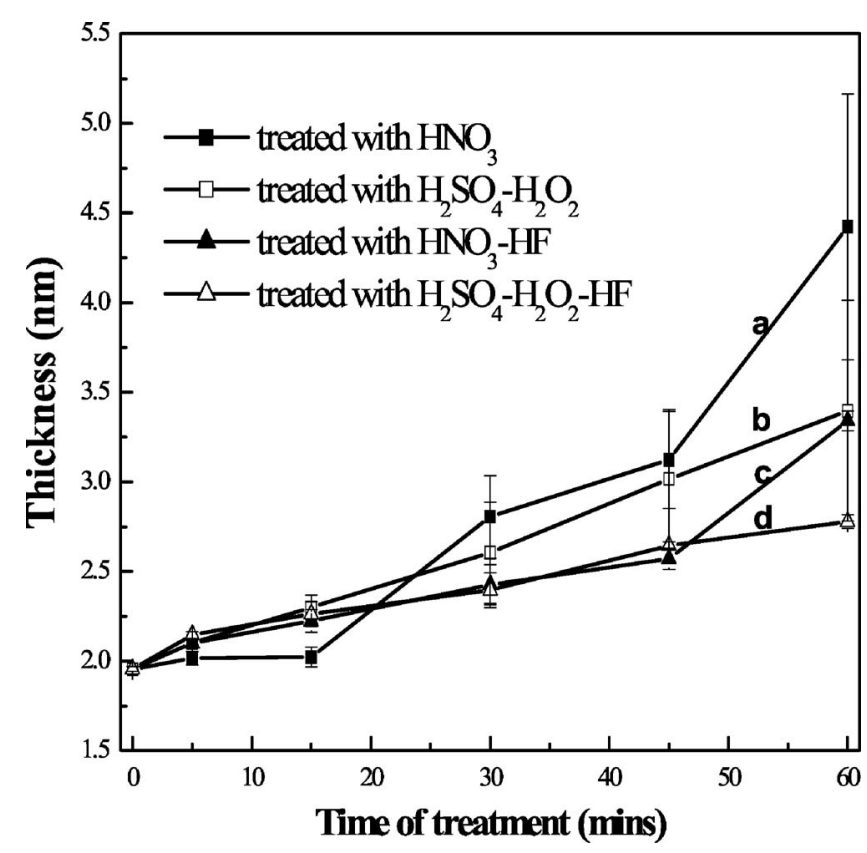

Figure 9. Change of thicknesses ( $\mathrm{nm}$ ) measured with ellipsometry for $\mathrm{Si}(100)$ surfaces (predipped in 1:20 v/v HF solution) treated (a) 20-70\% $\mathrm{HNO}_{3}$, (b) $4: 1 \mathrm{v} / \mathrm{v}$ mixture of $90-98 \% \mathrm{H}_{2} \mathrm{SO}_{4}$ and $30-50 \% \mathrm{H}_{2} \mathrm{O}_{2}$, (c) mixture of $20-70 \% \mathrm{HNO}_{3}$ and $500 \mathrm{ppm} \mathrm{HF}$, (d) $4: 1 \mathrm{v} / \mathrm{v}$ mixture of $90-98 \%$ $\mathrm{H}_{2} \mathrm{SO}_{4}, 30-50 \% \mathrm{H}_{2} \mathrm{O}_{2}$ and 100 ppm HF for different contact times, followed by DI water rinsing and drying in nitrogen atmosphere. trolled oxidation on surface in the presence of HF in acid mixture by competitive oxidation-etching reaction. All thickness values are recorded in Table I.

DRIFTS analysis, coupled with a method developed by Pliskin and modified by Nagasawa, was used to quantitatively assess the surface hydroxyl group density. ${ }^{22,23}$ Assuming that density of the $\mathrm{SiO}_{2}$ film is $2.2 \mathrm{~g} / \mathrm{cm}^{3}$ and $\mathrm{A}^{\prime}$ is the absorptivity per $\mathrm{cm}$ of film, the number of $\mathrm{SiOH}$ in $\mathrm{cm}^{2}\left(\mathrm{~N}_{\mathrm{OH}}\right)$ can be obtained as follows

$$
\mathrm{N}_{\mathrm{OH}}^{\prime}=2.4 \times 10^{16} \times \mathrm{H} \times \mathrm{A}_{3650}^{\prime} \times t
$$

where $t$ is the thickness of the oxide film $(\mathrm{cm})$. Table I shows the results of the calculation according to Eq. 2 for the different surfaces prepared. A continuous increase in the number of hydroxyl groups for surfaces treated without HF was observed, but for the surfaces treated with SPFM and SE, there was an initial increase in the number of $\mathrm{SiOH}$ groups followed by a decrease at higher incubation times. This is in agreement with Fig. 8, where the qualitative $\mathrm{SiH}_{x}$ coverage was shown to increase logarithmically. An increase in hydrophilicity can be attributed to higher $\mathrm{SiOH}$ formation for surfaces treated with SPM and $\mathrm{HNO}_{3}$, observed from Table I. For surfaces treated with SPFM and SE, there was an initial increase in hydrophilicity due to the formation of $\mathrm{SiOH}$, whereas $\mathrm{SiH}_{x}$ formation was comparatively less. With longer reaction times, the formation of $\mathrm{SiH}_{x}$ dominated and attained saturation thereby making the surface hydrophobic. It is hypothesized that the concurrent formation of $\mathrm{SiOH}$ and $\mathrm{SiH}_{x}$ is a competitive process.

Contact angle analysis and measurement of absolute hydrophilicity.-Contact angle has been explored to estimate the absolute values of hydrophilicity, surface tension components and polar or apolar nature of the surfaces generated. Contact angles were measured using three polar liquids (DI water, ethylene glycol, and glycerol) and two apolar liquids (diiodomethane, $\alpha$-bromonaphthalene); $\alpha$-bromonaphthalene $\left(\gamma_{\mathrm{L}}^{+}=0, \quad \gamma_{\mathrm{L}}^{-}=0, \quad \gamma_{\mathrm{L}}^{\mathrm{LW}}=44.4 \mathrm{~mJ} / \mathrm{m}^{2}, \quad \gamma_{\mathrm{L}}\right.$ $=44.4 \mathrm{~mJ} / \mathrm{m}^{2}$ ) was used to calculate the apolar component of the surface energy while diiodomethane $\left(\gamma_{\mathrm{L}}^{+}=0.7 \mathrm{~mJ} / \mathrm{m}^{2}, \gamma_{\mathrm{L}}^{-}=0\right.$, $\left.\gamma_{\mathrm{L}}^{\mathrm{LW}}=50.8 \mathrm{~mJ} / \mathrm{m}^{2}, \quad \gamma_{\mathrm{L}}=50.8 \mathrm{~mJ} / \mathrm{m}^{2}\right)$, ethylene glycol $\left(\gamma_{\mathrm{L}}^{+}\right.$ $\left.=1.92 \mathrm{~mJ} / \mathrm{m}^{2}, \gamma_{\mathrm{L}}^{-}=47 \mathrm{~mJ} / \mathrm{m}^{2}, \gamma_{\mathrm{L}}^{\mathrm{LW}}=29 \mathrm{~mJ} / \mathrm{m}^{2}, \gamma_{\mathrm{L}}=48 \mathrm{~mJ} / \mathrm{m}^{2}\right)$ were used to calculate the polar component of the surfaces following the equations developed by Fowkes (Eq. 3) and Van OssChaudhury-Good (Eq. 4), respectively ${ }^{26}$

$$
\begin{gathered}
(1+\operatorname{Cos} \theta)=2\left(\gamma_{\mathrm{S}}^{\mathrm{LW}} / \gamma_{\mathrm{L}}^{\mathrm{LW}}\right)^{1 / 2} \\
(1+\operatorname{Cos} \theta) \gamma_{\mathrm{L}}=2\left[\left(\gamma_{\mathrm{S}}^{\mathrm{LW}} \cdot \gamma_{\mathrm{L}}^{\mathrm{LW}}\right)^{1 / 2}+\left(\gamma_{\mathrm{S}}^{+} \cdot \gamma_{\mathrm{L}}^{-}\right)^{1 / 2}+\left(\gamma_{\mathrm{S}}^{-} \cdot \gamma_{\mathrm{L}}^{+}\right)^{1 / 2}\right]
\end{gathered}
$$

$\theta$ is the contact angle between a drop of liquid and a chemically homogeneous, nonadsorbing, smooth and horizontal solid surface; S, L, LW subscripts correspond to solid, liquid, Lifshitz-van der Waals interactions for the apolar nature of surface; $\gamma$ stands for interfacial tension $\left(\mathrm{mJ} / \mathrm{m}^{2}\right) ; \gamma_{\mathrm{SL}}, \gamma_{\mathrm{S}}, \gamma_{\mathrm{L}}$ correspond to interfacial tension between solid surface and liquid, solid surface tension, liquid surface tension, respectively; $\gamma^{+}, \gamma^{-}$correspond to asymmetric electron-acceptor and electron-donor interactions between surface and liquid. The values of $\gamma_{S}^{+}, \gamma_{S}^{-}, \gamma_{S}^{\mathrm{LW}}$ depend on the functional groups present on the surface. A quantitative estimation of hydrophilicity is possible through knowledge of the surface polarity and the free energy of hydration (i.e., the interaction free energy between a surface and water, $\left.\Delta G_{\text {sw }}\right)$, Gibbs free energy of hydration $\left(\Delta G_{\text {sws }}\right)$ and the rule coined by Van Oss. According to Van Oss, a substrate will be hydrophilic or less hydrophilic (hydrophobic) depending on $^{24,25}$

$$
\Delta G_{\mathrm{sws}}>0, \Delta G_{\mathrm{sw}}<-113 \mathrm{~mJ} / \mathrm{m}^{2}
$$

substrate is hydrophilic or more hydrophilic 
Table I. Thickness (nm) measured with ellipsometry and corresponding number of surface hydroxyl groups (-SiOH) per $\mathrm{cm}^{2}$ of surface area (calculated using Pliskin method) of $\mathrm{Si}(100)$ surfaces (predipped in 1:20 v/v HF solution) treated with (a) 20-70\% $\mathrm{HNO}_{3}$, (b) 4:1 v/v mixture of $90-98 \% \mathrm{H}_{2} \mathrm{SO}_{4}$ and 30-50\% $\mathrm{H}_{2} \mathrm{O}_{2}$, (c) mixture of 20-70\% $\mathrm{HNO}_{3}$ and $500 \mathrm{ppm} \mathrm{HF}$, (d) 4:1 v/v mixture of 90-98\% $\mathrm{H}_{2} \mathrm{SO}_{4}, 30-50 \% \mathrm{H}_{2} \mathrm{O}_{2}$, and $100 \mathrm{ppm} \mathrm{HF}$ for different contact times, followed by DI water rinsing and drying in nitrogen atmosphere.

\begin{tabular}{|c|c|c|c|c|c|c|c|c|}
\hline \multirow[b]{2}{*}{$\begin{array}{l}\text { Time } \\
(\mathrm{min})\end{array}$} & \multicolumn{2}{|c|}{$\mathrm{HNO}_{3}$} & \multicolumn{2}{|c|}{$\mathrm{H}_{2} \mathrm{SO}_{4}-\mathrm{H}_{2} \mathrm{O}_{2}$} & \multicolumn{2}{|c|}{$\mathrm{HNO}_{3}-\mathrm{HF}$} & \multicolumn{2}{|c|}{$\mathrm{H}_{2} \mathrm{SO}_{4}-\mathrm{H}_{2} \mathrm{O}_{2}-\mathrm{HF}$} \\
\hline & $\begin{array}{c}\text { Thickness } \\
(\mathrm{nm})\end{array}$ & $\begin{array}{c}\text { No. of } \\
\text { SiOH per } \\
\text { unit area } \\
\left(\times 10^{14} \mathrm{~cm}^{2}\right)\end{array}$ & $\begin{array}{c}\text { Thickness } \\
(\mathrm{nm})\end{array}$ & $\begin{array}{c}\text { No. of } \\
\text { SiOH per } \\
\text { unit area } \\
\left(\times 10^{14} \mathrm{~cm}^{2}\right)\end{array}$ & $\begin{array}{c}\text { Thickness } \\
(\mathrm{nm})\end{array}$ & $\begin{array}{c}\text { No. of } \\
\text { SiOH per } \\
\text { unit area } \\
\left(\times 10^{14} \mathrm{~cm}^{2}\right)\end{array}$ & $\begin{array}{c}\text { Thickness } \\
(\mathrm{nm})\end{array}$ & $\begin{array}{c}\text { No. of } \\
\text { SiOH per } \\
\text { unit area } \\
\left(\times 10^{14} \mathrm{~cm}^{2}\right)\end{array}$ \\
\hline 0 & 1.9 & - & 1.9 & - & 1.9 & - & 1.9 & - \\
\hline 5 & 2.0 & 0.1 & 2.1 & 0.3 & 2.1 & 0.4 & 2.1 & 0.5 \\
\hline 15 & 2.0 & 0.5 & 2.3 & 0.4 & 2.2 & 0.4 & 2.3 & 0.5 \\
\hline 30 & 2.8 & 0.9 & 2.6 & 0.7 & 2.4 & 0.6 & 2.4 & 0.4 \\
\hline 45 & 3.1 & 1.2 & 3.0 & 1.3 & 2.6 & 0.4 & 2.6 & 0.1 \\
\hline 60 & 4.4 & 2.7 & 3.4 & 1.7 & 3.3 & 0.1 & 2.8 & 0.3 \\
\hline
\end{tabular}

$$
\Delta G_{\text {sws }}<0, \Delta G_{\text {sw }}>-113 \mathrm{~mJ} / \mathrm{m}^{2}
$$

substrate is hydrophobic or less hydrophilic.

$\Delta G_{\mathrm{sw}}$ and $\Delta G_{\mathrm{sws}}$ can be obtained from the Young-Dupre equation and the following equations respectively ${ }^{25,26}$

$$
\begin{gathered}
\Delta G_{\mathrm{sw}}=-\gamma_{\mathrm{w}}^{\mathrm{T}}\left(1+\cos \theta_{\mathrm{w}}\right) \\
\gamma_{\mathrm{sw}}^{\mathrm{T}}=\left[\gamma_{\mathrm{sw}}^{\mathrm{LW}}-\left(\gamma_{\mathrm{sw}}^{\mathrm{LW}}\right)^{1 / 2}\right]+2\left[\left\{\left(\gamma_{\mathrm{s}}^{+}\right)^{1 / 2}-\left(\gamma_{\mathrm{w}}^{+}\right)^{1 / 2}\right\}\left\{\left(\gamma_{\mathrm{s}}^{-}\right)^{1 / 2}-\left(\gamma_{\mathrm{w}}^{-}\right)^{1 / 2}\right\}\right]
\end{gathered}
$$

$$
\Delta G_{\mathrm{sws}}=-2 \gamma_{\mathrm{sw}}
$$

where, $\gamma_{\mathrm{w}}^{\mathrm{T}}$ is the total surface tension of water $\left(\gamma_{\mathrm{w}}^{\mathrm{T}}=72.8 \mathrm{~mJ} / \mathrm{m}^{2}\right)$, $\theta_{\mathrm{w}}$ is the contact angle measured with DI water and $\gamma_{\mathrm{sw}}^{\mathrm{T}}$, the total interfacial tension between the silicon surface and water.

The change in contact angle, when measured with water, for different incubation times in the oxidizing-etching solution, is shown in Fig. 10. In the case of surfaces treated with oxidizing acid solution (without HF), the contact angle was observed to decrease continuously indicating an increase in the hydrophilic nature of the surface. However, for surfaces, treated with oxidizing-etching mixtures that included HF, contact angle values were observed to decrease initially, indicating the hydrophilic nature of the surface. After $15 \mathrm{~min}$, an increase in the contact angle values was observed indicating an increase in the hydrophobic nature of the surface. Similar trends were observed when surface contact angles were measured with other polar liquids like ethylene glycol and glycerol. The values are summarized in Table II. Using Eq. 3 and 4, the apolar and polar components (with both negative and positive polar component) of hydroxylated wafers were calculated and the change of negative polar component of surface tension $\left(\gamma_{\mathrm{S}}^{-}\right)$with time of treatment is shown in Fig. 9. The apolar component of surface tension variation was similar to the contact angle variation. The variation of positive polar component was very small and negligible; hence the surface can be identified as unipolar with negative charge on the surface.

The electron donation interaction component, or negative polar component of surface tension $\left(\gamma_{\mathrm{S}}^{-}\right)$, is proportional to the number of electron donating groups, which is the hydroxyl group here. The electron donation interaction component $\left(\gamma_{\mathrm{S}}^{-}\right)$increased continuously through 60 min for surfaces treated with oxidizing acid mixture without HF indicating increasing hydrophilicity. This fact is further confirmed from the increasing number of $-\mathrm{SiOH}$ groups on the surface from Table I. However, $\gamma_{S}^{-}$for surfaces treated with oxidizing-etching acid mixture with $\mathrm{HF}$ showed a decrease after 15 min of treatment indicating the hydrophobic nature of the surface. Total surface tension change calculation $\left(\gamma_{\mathrm{S}}\right)$, obtained by the summation of $\gamma_{\mathrm{S}}^{\mathrm{LW}}$ and 2. $\left(\gamma_{\mathrm{S}}^{+} \cdot \gamma_{\mathrm{S}}^{-}\right)$, showed an initial increase for the surface treated with oxidizing acid mixture without HF, which finally reaches saturation (not shownin figure). In the case of surfaces treated with oxidizing-etching acid mixture with $\mathrm{HF}$, a decrease in $\gamma_{\mathrm{S}}$ was noticeable from 15 min onward after an initial increase indicating the hydrophobic nature of the surface. The values of $\gamma_{S}$ from the oxidizing-etching acid mixture treated surfaces after 45 or 60 min were similar to bare, unmodified, hydrophobic silicon wafer. The only reason for developed hydrophobicity was attributed to the formation of $\mathrm{SiH}_{x}$ which was further confirmed from Table I (decreasing number of $-\mathrm{SiOH}$ groups) and Fig. 8 (logarithmic increase of $\left.\mathrm{SiH}_{x}\right)$. Different values for calculated $\Delta G_{\mathrm{sws}}, \Delta G_{\mathrm{sw}}$ are summarized in Table III. From this table and following the above rule developed by Van Oss, it can be concluded that surfaces treated for 30,45 and 60 min without $\mathrm{HF}$ in acid mixture, were more hydrophilic than surfaces treated for 5 and 15 min. Again, surfaces were more hydrophilic below30 min (approx.) when treated with HF in acid mixture than those surfaces treated for longer than $30 \mathrm{~min}$.

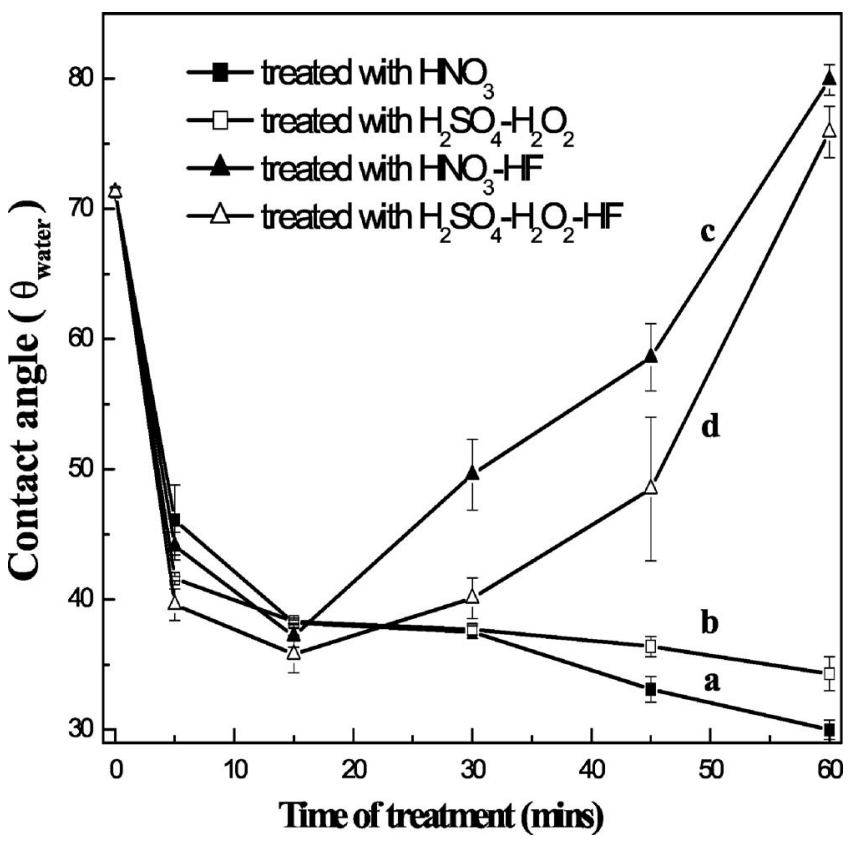

Figure 10. Change of contact angles $\left(\theta_{\text {water }}\right.$, measured with water), for $\mathrm{Si}(100)$ surfaces treated with (a) $20-70 \% \mathrm{HNO}_{3}$, (b) $4: 1 \mathrm{v} / \mathrm{v}$ mixture of 90-98\% $\mathrm{H}_{2} \mathrm{SO}_{4}$ and $30-50 \% \mathrm{H}_{2} \mathrm{O}_{2}$, (c) mixture of $20-70 \% \mathrm{HNO}_{3}$ and $500 \mathrm{ppm} \mathrm{HF}$, (d) $4: 1 \mathrm{v} / \mathrm{v}$ mixture of $90-98 \% \mathrm{H}_{2} \mathrm{SO}_{4}, 30-50 \% \mathrm{H}_{2} \mathrm{O}_{2}$, and $100 \mathrm{ppm} \mathrm{HF}$ for different contact times, followed by DI water rinsing and drying in nitrogen atmosphere. 
Table II. Contact angles ( $\theta$ ) measured with water (w), ethylene glycol (EG), glycerol (G) for $\mathrm{Si}(100)$ surfaces treated with (a) $20-70 \% \mathrm{HNO}_{3}$, (b) $4: 1 \mathrm{v} / \mathrm{v}$ mixture of $90-98 \% \mathrm{H}_{2} \mathrm{SO}_{4}$ and $30-50 \% \mathrm{H}_{2} \mathrm{O}_{2}$, (c) mixture of $20-70 \% \mathrm{HNO}_{3}$ and $500 \mathrm{ppm} \mathrm{HF}$, (d) 4:1 v/v mixture of 90-98\% $\mathrm{H}_{2} \mathrm{SO}_{4}, 30-50 \% \mathrm{H}_{2} \mathrm{O}_{2}$, and $100 \mathrm{ppm} \mathrm{HF}$ for different contact times, followed by DI water rinsing and dried in nitrogen atmosphere.

\begin{tabular}{|c|c|c|c|c|c|c|c|c|c|c|c|c|}
\hline \multirow[b]{2}{*}{$\begin{array}{l}\text { Time } \\
(\min )\end{array}$} & \multicolumn{3}{|c|}{$\mathrm{HNO}_{3}$} & \multicolumn{3}{|c|}{$\mathrm{H}_{2} \mathrm{SO}_{4}-\mathrm{H}_{2} \mathrm{O}_{2}$} & \multicolumn{3}{|c|}{$\mathrm{HNO}_{3}-\mathrm{HF}$} & \multicolumn{3}{|c|}{$\mathrm{H}_{2} \mathrm{SO}_{4}-\mathrm{H}_{2} \mathrm{O}_{2}-\mathrm{HF}$} \\
\hline & $\theta_{\mathrm{W}}$ & $\theta_{\mathrm{EG}}$ & $\theta_{\mathrm{G}}$ & $\theta_{\mathrm{W}}$ & $\theta_{\mathrm{EG}}$ & $\theta_{\mathrm{G}}$ & $\theta_{\mathrm{W}}$ & $\theta_{\mathrm{EG}}$ & $\theta_{\mathrm{G}}$ & $\theta_{\mathrm{W}}$ & $\theta_{\mathrm{EG}}$ & $\theta_{\mathrm{G}}$ \\
\hline 0 & 71.3 & 50.5 & 77.1 & 71.3 & 50.5 & 77.1 & 71.3 & 44.1 & 37.2 & 71.3 & 44.1 & 37.2 \\
\hline 5 & 46.1 & 39.9 & 41.2 & 41.6 & 32.2 & 41.4 & 44.1 & 26.7 & 29.6 & 39.6 & 29.1 & 33.1 \\
\hline 15 & 38.2 & 31.1 & 37.1 & 38.3 & 27.8 & 37.8 & 37.2 & 20.1 & 27.3 & 35.8 & 21.1 & 32.5 \\
\hline 30 & 37.5 & 26.4 & 34.2 & 37.7 & 25.2 & 34.9 & 49.6 & 25.3 & 48.3 & 40.1 & 23.6 & 36.5 \\
\hline 45 & 33.1 & 23.7 & 33.1 & 36.4 & 24.2 & 33.3 & 58.6 & 27.3 & 55.8 & 48.5 & 26.3 & 38.4 \\
\hline 60 & 30.0 & 21.7 & 28.4 & 34.3 & 22.6 & 29.6 & 79.9 & 44.3 & 66.8 & 75.8 & 43.7 & 68.9 \\
\hline
\end{tabular}

From Fig. 8 and 10 and Table I, it can be concluded that an increase in the number of hydroxyl groups correlates with decreasing values of contact angles and $\gamma_{\mathrm{S}}^{\mathrm{LW}}$, and increasing values of $\gamma_{\mathrm{S}}^{-}$ for surfaces treated with $\mathrm{HNO}_{3}$ and $\mathrm{H}_{2} \mathrm{SO}_{4}-\mathrm{H}_{2} \mathrm{O}_{2}$. For surfaces treated with $\mathrm{HNO}_{3}-\mathrm{HF}$ and $\mathrm{H}_{2} \mathrm{SO}_{4}-\mathrm{H}_{2} \mathrm{O}_{2}-\mathrm{HF}$, with an initial increase in the number of hydroxyl groups, there was a competitive formation of $\mathrm{SiH}_{x}$. Initially, the concentration of $\mathrm{SiOH}$ was estimated to be more than $\mathrm{SiH}_{x}$, hence a decrease in contact angles and $\gamma_{\mathrm{S}}^{\mathrm{LW}}$ and an increase in $\gamma_{\mathrm{S}}^{-}$were observed. With longer reaction times, $\mathrm{SiH}_{x}$ coverage on surfaces was estimated to be more than $\mathrm{SiOH}$ coverage. This was supported by the increase in contact angle values and $\gamma_{\mathrm{S}}^{\mathrm{LW}}$.

Surface roughness determination by atomic force microscopy.Figure 11 shows the three-dimensional (3D) views of surfaces obtained with AFM imaging. Surface roughness of the hydroxylated wafers was similar except for surfaces treated with HF for 45 and $60 \mathrm{~min}$. These values were significantly higher than virgin wafer or wafer treated for $15 \mathrm{~min}$. Three-dimensional views have been shown for the surfaces treated with all four methods for 15 and $60 \mathrm{~min}$. $\mathrm{HNO}_{3}-\mathrm{HF}$ and $\mathrm{H}_{2} \mathrm{SO}_{4}-\mathrm{H}_{2} \mathrm{O}_{2}-\mathrm{HF}$ showed a large value of rms indicating a very rough surface. The virgin wafer had roughness of $0.268 \mathrm{~nm}$ (not shown) which increased by 3.5 times for the surface treated with $\mathrm{HNO}_{3}-\mathrm{HF}$ and 2.8 times for the surface treated with $\mathrm{H}_{2} \mathrm{SO}_{4}-\mathrm{H}_{2} \mathrm{O}_{2}-\mathrm{HF}$ for $60 \mathrm{~min}$. These results could serve as a precautionary measure for not using these methods for longer reaction times where roughness may be a factor.

In the separate control experiments, the surfaces were exposed to different oxidizing $\left(\mathrm{HNO}_{3}, \mathrm{SPM}\right)$ and oxidizing-etching (SE, SPFM) solution for the same reaction times without any HF predip and characterized with DRIFTS and ellipsometry. Ellipsometry showed (figure not shown) high thickness values for all the surfaces (not predipped in $\mathrm{HF}$ ) treated with oxidizing $\left(\mathrm{HNO}_{3}, \mathrm{SPM}\right)$ and oxidizing-etching (SE, SPFM) solution, compared to surfaces predipped with HF. Area calculation for $\mathrm{Si}-\mathrm{O}$ in the DRIFTS spectra in the region of $980-1300 \mathrm{~cm}^{-1}$, showed much higher values for acid mixtures treated surfaces without HF predip than with HF predip. The calculated of number of hydroxyl groups, based on Pliskin methods, showed almost similar values for acid mixtures treated surfaces without HF predip to surfaces with HF predip (figure not shown).

Analysis of results and mechanism.- From the results discussed above, it was quite evident that hydrophilicity due to silanol group was found to increase for treatments without $\mathrm{HF}\left(\mathrm{SPM}\right.$ and $\left.\mathrm{HNO}_{3}\right)$, and there was no evidence of $\mathrm{SiH}_{x}$ formation from DRIFTS and contact angle analysis. However, there was significant change observed in the treatment with SPFM and SE where HF was added in ppm level. The number of hydroxyl group is increasing initially and then decreasing as shown in the Table I. Surface coverage plot of $\mathrm{SiH}_{x}$ (Fig. 7) also shows a logarithmic increase of $\mathrm{SiH}_{x}$ which saturates after $45 \mathrm{~min}$ for both SPFM and SE treated surfaces separately. Therefore competition must exist between etching reaction and oxidation, resulting in less $\mathrm{SiOH}$ than $\mathrm{SiH}_{x}$ after a certain reaction time. Based on the mechanism published earlier, ${ }^{4,19}$ an alternative reaction mechanism (Fig. 12) has been proposed to better explain the results.

The native chemical oxides on bare silicon wafer are different from wet chemically grown oxide because of the oxygen bound to the silicon surface. ${ }^{4}$ Native oxide has siloxane rings which are very stable against hydrolysis, rendering the surface highly hydrophobic; 1:20 v/v HF-water mixture (1.1-1.2 M) treatment etches the hydrophobic native $\mathrm{SiO}_{2}$ layer following the reaction, as denoted by Eq. 8 and leaves the surface hydrogen passivated ${ }^{19}$

$$
\mathrm{SiO}_{2}+\mathrm{HF}=2 \mathrm{H}^{+}+\mathrm{SiF}_{6}^{-}+2 \mathrm{H}_{2} \mathrm{O}
$$

In diluted $\mathrm{HF}, \mathrm{HF}$ dissociates forming $\mathrm{H}^{+}, \mathrm{F}^{-}, \mathrm{HF}_{2}^{-}$and $\mathrm{HF}$ dimerizes (as denoted by Eq. $9-11 .{ }^{17}$ The etching reaction of $\mathrm{SiO}_{2}$ with $\mathrm{HF}$ included, involves $\mathrm{H}^{+}, \mathrm{F}^{-}, \mathrm{HF}_{2}^{-},(\mathrm{HF})_{2}$

$$
\begin{gathered}
\mathrm{HF}=\mathrm{H}^{+}+\mathrm{F}^{-} \\
\mathrm{HF}+\mathrm{F}^{-}=\mathrm{HF}_{2}^{-}
\end{gathered}
$$

Table III. Change of Gibbs free energy $\left(-\Delta G_{\mathrm{SW}}, \mathrm{mJ} / \mathrm{m}^{2}\right)$ and free energy of hydration $\left(-\Delta G_{\mathrm{SwS}}, \mathrm{mJ} / \mathrm{m}^{2}\right)$ for $\mathrm{Si}(100)$ surfaces (predipped in $1: 20 \mathrm{v} / \mathrm{v}$ HF solution) treated with (a) 20-70\% $\mathrm{HNO}_{3}$, (b) $4: 1 \mathrm{v} / \mathrm{v}$ mixture of $90-98 \% \mathrm{H}_{2} \mathrm{SO}_{4}$ and 30-50\% $\mathrm{H}_{2} \mathrm{O}_{2}$, (c) mixture of $20-70 \% \mathrm{HNO}_{3}$

\begin{tabular}{|c|c|c|c|c|c|c|c|c|}
\hline \multirow{2}{*}{$\begin{array}{l}\text { Time } \\
(\mathrm{min})\end{array}$} & \multicolumn{2}{|c|}{$\mathrm{HNO}_{3}$} & \multicolumn{2}{|c|}{$\mathrm{H}_{2} \mathrm{SO}_{4}-\mathrm{H}_{2} \mathrm{O}_{2}$} & \multicolumn{2}{|c|}{$\mathrm{HNO}_{3}-\mathrm{HF}$} & \multicolumn{2}{|c|}{$\mathrm{H}_{2} \mathrm{SO}_{4}-\mathrm{H}_{2} \mathrm{O}_{2}-\mathrm{HF}$} \\
\hline & $-\Delta G_{\mathrm{sw}}$ & $-\Delta G_{\mathrm{sws}}$ & $-\Delta G_{\mathrm{sw}}$ & $-\Delta G_{\mathrm{sws}}$ & $-\Delta G_{\mathrm{sw}}$ & $-\Delta G_{\text {sws }}$ & $-\Delta G_{\mathrm{sw}}$ & $-\Delta G_{\mathrm{sws}}$ \\
\hline 0 & -96.1 & -45.2 & -96.1 & -45.2 & -96.1 & -45.2 & -96.1 & -45.2 \\
\hline 5 & -123.1 & -29 & -127.2 & -2.3 & -125.0 & 1.6 & -128.9 & -12.1 \\
\hline 15 & -130 & -12.1 & -129.9 & 4.5 & -130.8 & 10.2 & -131.8 & 27.9 \\
\hline 30 & -130.5 & 12.8 & -130.4 & 16.9 & -119.9 & -17.1 & -128.4 & 11.9 \\
\hline 45 & -133.8 & 20.6 & -131.4 & 27.8 & -110.6 & -38.9 & -120.6 & -7.1 \\
\hline 60 & -135.8 & 35.6 & -132.9 & 34.7 & -85.6 & -54.6 & -90.6 & -27.8 \\
\hline
\end{tabular}
and $500 \mathrm{ppm} \mathrm{HF}$, (d) 4:1 v/v mixture of $90-98 \% \mathrm{H}_{2} \mathrm{SO}_{4}, 30-50 \% \mathrm{H}_{2} \mathrm{O}_{2}$, and $100 \mathrm{ppm} \mathrm{HF}$ for different contact times, followed by DI water rinsing and drying in nitrogen atmosphere. 

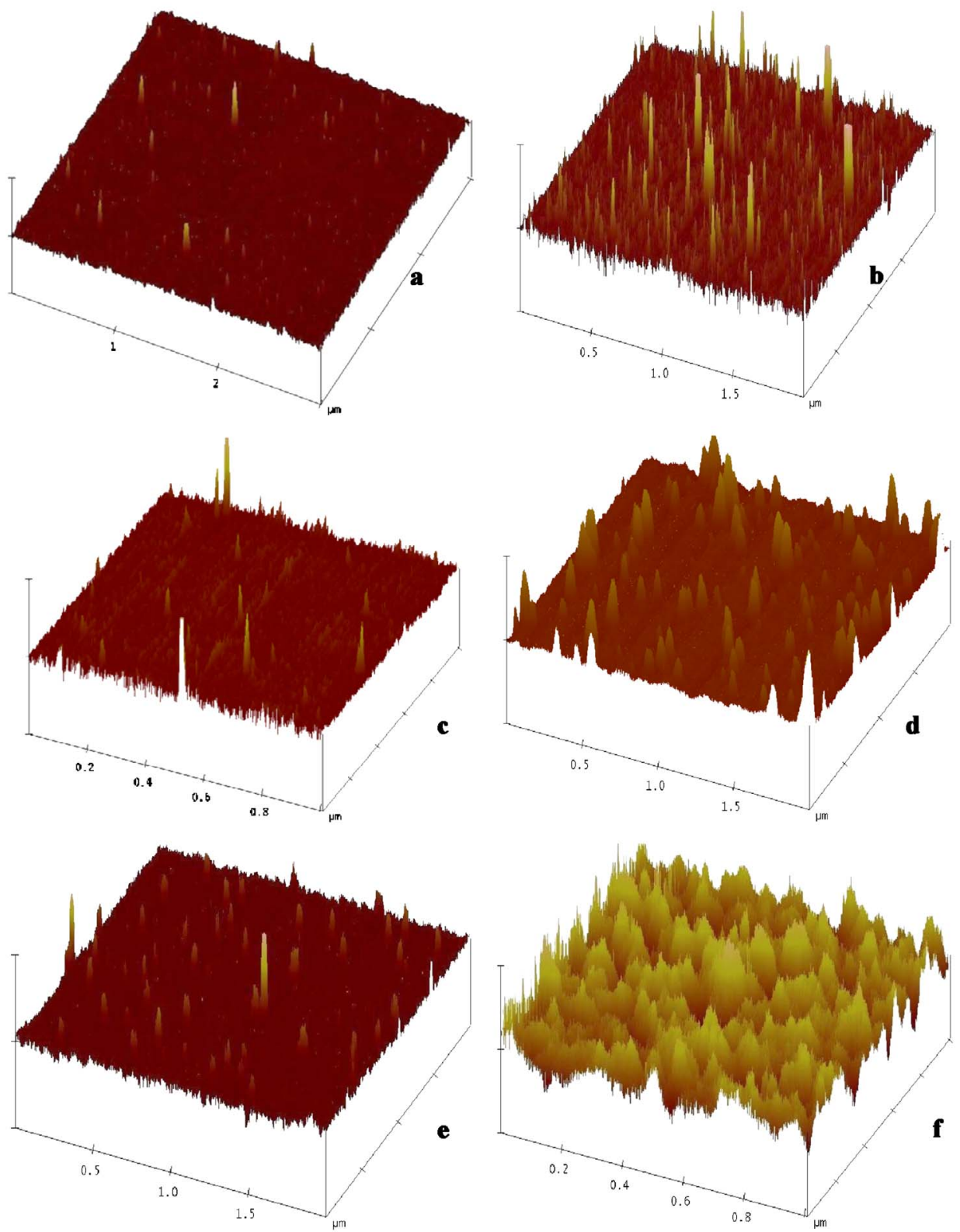

Figure 11. (Color online) Threedimensional views of the $\mathrm{Si}(100)$ treated with (a) $\mathrm{HNO}_{3}$ for $15 \mathrm{~min}$ (rms: $0.288 \mathrm{~nm}$ ), (b) $\mathrm{HNO}_{3}$ for $60 \mathrm{~min}(\mathrm{rms}$ : $0.689 \mathrm{~nm}$ ), (c) $\mathrm{H}_{2} \mathrm{SO}_{4}-\mathrm{H}_{2} \mathrm{O}_{2}$ for $15 \mathrm{~min}$ (rms: $0.204 \mathrm{~nm}$ ), (d) $\mathrm{H}_{2} \mathrm{SO}_{4}-\mathrm{H}_{2} \mathrm{O}_{2}$ for $60 \min (0.565 \mathrm{~nm})$, (e) $\mathrm{HNO}_{3}-\mathrm{HF}$ for $15 \mathrm{~min}$ (rms: $0.382 \mathrm{~nm}$ ), (f) $\mathrm{HNO}_{3}-\mathrm{HF}$ for $60 \mathrm{~min}$ rms: $1.202 \mathrm{~nm}), \quad(\mathrm{g})$ $\mathrm{H}_{2} \mathrm{SO}_{4}-\mathrm{H}_{2} \mathrm{O}_{2}-\mathrm{HF}$ for $15 \mathrm{~min}$ (rms: $0.357 \mathrm{~nm}), \quad$ (h) $\mathrm{H}_{2} \mathrm{SO}_{4}-\mathrm{H}_{2} \mathrm{O}_{2}-\mathrm{HF}$ for $60 \mathrm{~min}$ (rms: $0.962 \mathrm{~nm}$ ) reaction time.
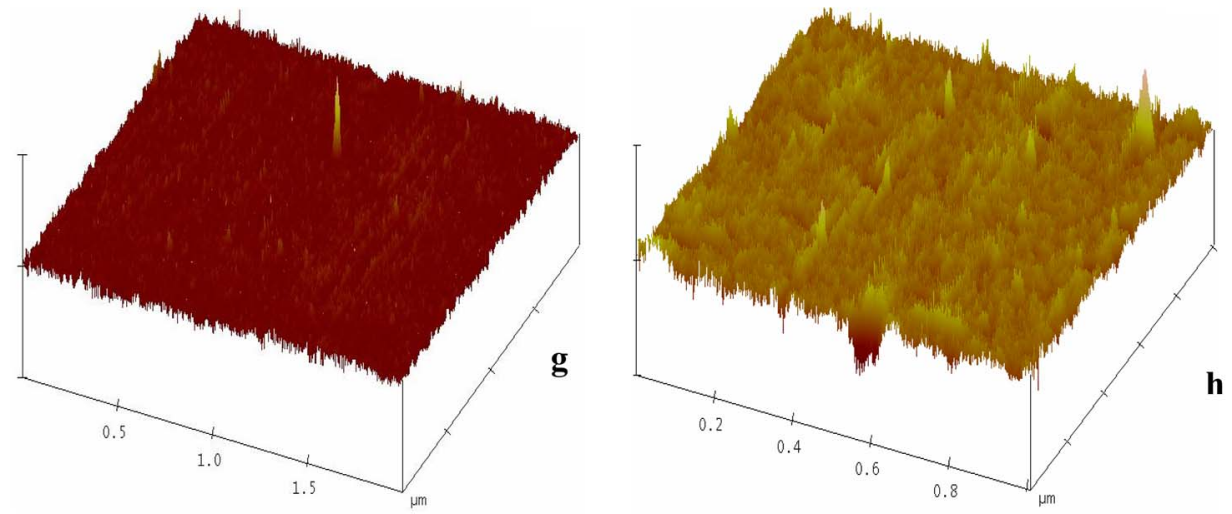

h

$$
2 \mathrm{HF}=(\mathrm{HF})_{2}
$$

It was reported that $\mathrm{HF}$ is a very weak acid above $1 \mathrm{M}$ and etching is carried out mainly by $\mathrm{HF}$ and $(\mathrm{HF})_{2}$ due to nondissociation of
$\mathrm{HF}\left(\mathrm{HF}>(\mathrm{HF})_{2} \gg \mathrm{H}^{+}>\left(\mathrm{HF}_{2}\right)^{-} \approx(\mathrm{HF})_{n} \mathrm{~F}^{-} \approx \mathrm{F}^{-}\right) .{ }^{17}$ The etching rate is low correspondingly as etching of $\mathrm{SiO}_{2}$ mainly takes place with $\mathrm{HF}_{2}^{-}$. Concentrations and corresponding $\mathrm{pH}$ measure- 


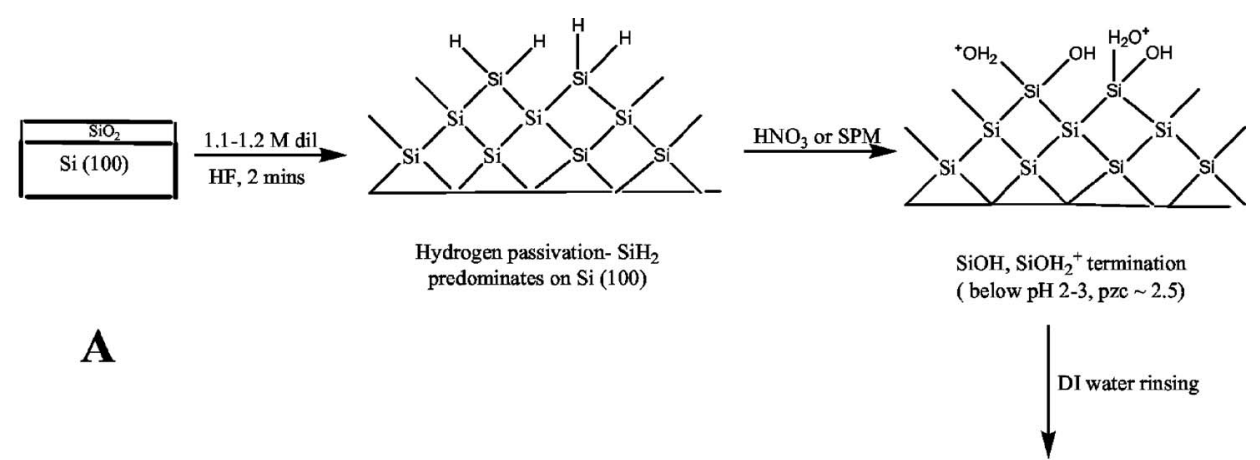

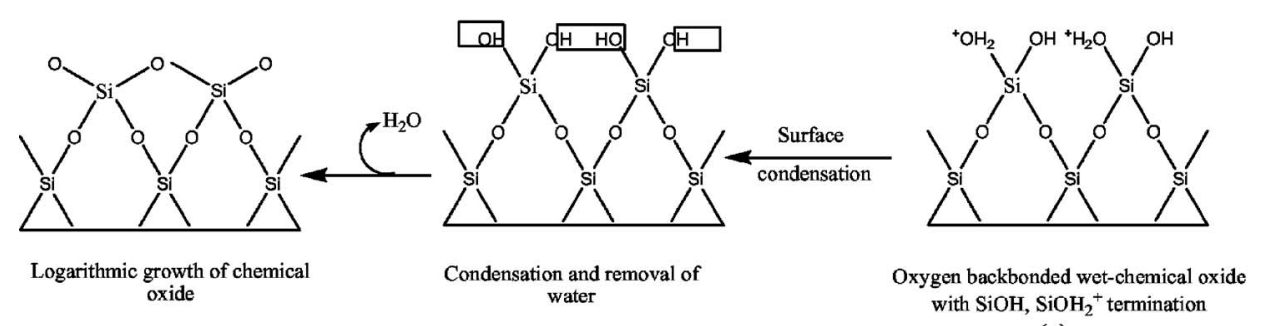

(a)
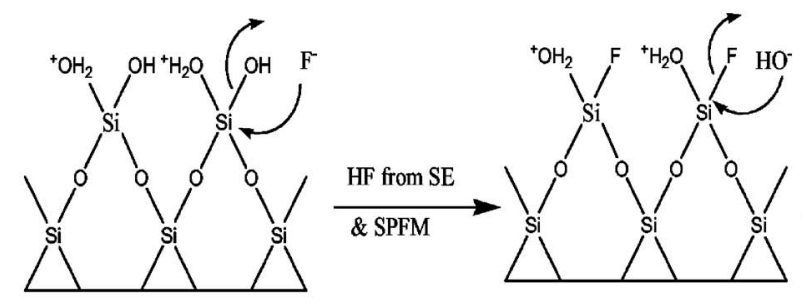

$\mathrm{Si}(\mathrm{OH})_{3} \mathbf{F}$

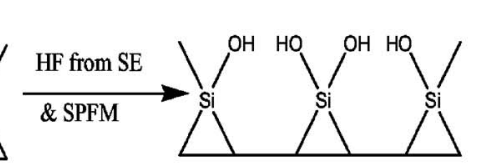

Figure 12. (A) Schematic representation of generation of wet-chemical oxide with $\mathrm{SiOH}$ termination for $\mathrm{Si}(100)$ surfaces (predipped in 1:20 v/v HF solution), treated with $20-70 \% \mathrm{HNO}_{3}$ or $4: 1 \mathrm{v} / \mathrm{v}$ mixture of $90-98 \% \mathrm{H}_{2} \mathrm{SO}_{4}$ and $30-50 \%$ $\mathrm{H}_{2} \mathrm{O}_{2}$. Condensation of two neighboring $\mathrm{SiOH}$ groups lead to the formation of $\mathrm{Si}-\mathrm{O}-\mathrm{Si}$ bridge, (B) When treated with mixture of $20-70 \% \mathrm{HNO}_{3}$ and $500 \mathrm{ppm}$ $\mathrm{HF}$ or $4: 1 \mathrm{v} / \mathrm{v}$ mixture of $90-98 \% \mathrm{H}_{2} \mathrm{SO}_{4}$, $30-50 \% \quad \mathrm{H}_{2} \mathrm{O}_{2}$ and $100 \mathrm{ppm} \mathrm{HF}$, along with the formation of $\mathrm{SiOH}$ terminated chemical oxide (a), competitive etching of it takes place resulting in the formation of $\mathrm{SiH}_{x}$ terminated surface (e) of different $\mathrm{SiH}_{2}$ configuration.

(a)

(b)

Oxygen backbonded wet-chemical oxide with $\mathrm{SiOH}, \mathrm{SiOH}_{2}^{+}$termination formed in SE and SPFM

B

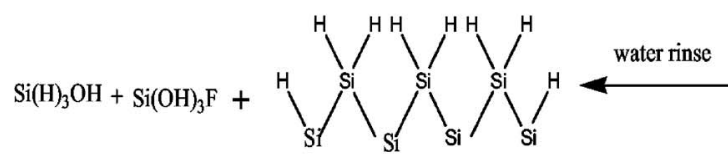

(e)

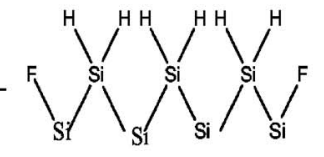

(d)
Direct adsorption of $\mathrm{H}$ at surface terminationat surface step dangling bond to form $\mathrm{SiH}_{2} ; \mathrm{F}$ (c)

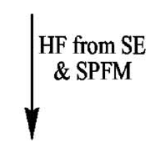

\& SPFM 


\section{Table IV. Concentration and $\mathrm{pH}$ of (a) 20-70\% $\mathrm{HNO}_{3}$, (b) 4:1 v/v mixture of 90-98\% $\mathrm{H}_{2} \mathrm{SO}_{4}$ and 30-50\% $\mathrm{H}_{2} \mathrm{O}_{2}$, (c) mixture of 20-70\% $\mathrm{HNO}_{3}$} and $500 \mathrm{ppm} \mathrm{HF}$, (d) $4: 1 \mathrm{v} / \mathrm{v}$ mixture of $90-98 \% \mathrm{H}_{2} \mathrm{SO}_{4}, 30-50 \% \mathrm{H}_{2} \mathrm{O}_{2}$, and $100 \mathrm{ppm} \mathrm{HF}$.

\begin{tabular}{|c|c|c|c|c|}
\hline Composition & & Concentration & $\mathrm{pH}$ & $\begin{array}{l}\text { Components, } \\
\text { ions, associated } \\
\text { with treatments }\end{array}$ \\
\hline$(1: 20 \mathrm{v} / \mathrm{v}) \mathrm{HF}:$ water & & $1.1-1.2 \mathrm{M}$ & $0.1-0.2$ & $\mathrm{HF},(\mathrm{HF})_{2}$ \\
\hline $\mathrm{HNO}_{3}$ & & $3.2-11.1 \mathrm{M}$ & $1.4-1.5$ & $\mathrm{H}_{3} \mathrm{O}^{+}, \mathrm{NO}_{3}^{-}$ \\
\hline $\mathrm{H}_{2} \mathrm{SO}_{4}-\mathrm{H}_{2} \mathrm{O}_{2}$ & $\begin{array}{l}\mathrm{H}_{2} \mathrm{SO}_{4} \\
\mathrm{H}_{2} \mathrm{O}_{2}\end{array}$ & $\begin{array}{c}13.3-14.7 \mathrm{M} \\
1.8-2.9 \mathrm{M}\end{array}$ & $1.2-1.5$ & $\begin{array}{c}\mathrm{H}_{3} \mathrm{O}^{+}, \mathrm{H}_{3} \mathrm{SO}_{4}^{+}, \mathrm{HSO}_{4}^{-} \\
\mathrm{SO}_{4}^{=}, \mathrm{H}_{2} \mathrm{SO}_{5}\end{array}$ \\
\hline $\mathrm{HNO}_{3}-\mathrm{HF}$ & $\begin{array}{l}\mathrm{HNO}_{3} \\
\mathrm{HF}\end{array}$ & $\begin{array}{c}3.2-11.1 \mathrm{M} \\
(5.7-6.1) \times 10^{-4} \mathrm{M}\end{array}$ & $0.2-0.4$ & $\begin{array}{c}\mathrm{H}_{3} \mathrm{O}^{+}, \mathrm{NO}_{3}^{-}, \mathrm{HF} \\
(\mathrm{HF})_{2}\end{array}$ \\
\hline $\mathrm{H}_{2} \mathrm{SO}_{4}-\mathrm{H}_{2} \mathrm{O}_{2}-\mathrm{HF}$ & $\begin{array}{l}\mathrm{H}_{2} \mathrm{SO}_{4} \\
\mathrm{H}_{2} \mathrm{O}_{2} \\
\mathrm{HF}\end{array}$ & $\begin{array}{c}13.3-14.7 \mathrm{M} \\
1.8-2.9 \mathrm{M} \\
(2.4-2.5) \times 10^{-3} \mathrm{M}\end{array}$ & $0.1-0.4$ & $\begin{array}{c}\mathrm{H}_{3} \mathrm{O}^{+}, \mathrm{H}_{3} \mathrm{SO}_{4}^{+}, \mathrm{HSO}_{4}^{-}, \\
\mathrm{SO}_{4}^{-}, \mathrm{H}_{2} \mathrm{SO}_{5}, \\
\mathrm{HF},(\mathrm{HF})_{2}\end{array}$ \\
\hline
\end{tabular}

$\mathrm{SiOH}$ group formations accompanied by logarithmic increase of oxide with time (see Table I and II and Fig. 9). ${ }^{21}$

$\mathrm{HF}$ is very strong below $0.05 \mathrm{M}$ and dissociates readily $\left(\mathrm{HF} \gg \mathrm{H}^{+}>\mathrm{F}^{-} \approx\left(\mathrm{HF}_{2}\right) \approx\left(\mathrm{HF}_{2}\right)^{-} \approx(\mathrm{HF}){ }_{n} \mathrm{~F}^{-}\right){ }^{17}$ Etching with such a solution takes place mainly through $\left(\mathrm{HF}_{2}\right)^{-}$and the rate is higher. It was shown that the addition of acid in diluted HF moves the equilibrium of Reaction 8 toward the left which in turn results in nil or minimal formation of $\mathrm{HF}_{2}^{-}$due to the unavailability of $\mathrm{F}^{-}{ }^{17}$ Only HF and $(\mathrm{HF})_{2}$ will then be available in the oxide-etching mixture. This concept can be used here where we have added ppm level of HF in SE and SPFM. Addition of HF reduces pH of the SE and SPFM solution toward 0.2-0.4 from 1.0 to 1.5 (see Table 4). In such low $\mathrm{pH}$ solution with the unavailability of $\left(\mathrm{HF}_{2}\right)^{-}$and $(\mathrm{HF})_{n} \mathrm{~F}^{-}$, dissolution of $\mathrm{SiO}_{2}$ is low and the surface is mainly terminated with $\mathrm{SIH}_{2}$. The reaction mechanism follows the same path of Fig. 12A with the formation of $\mathrm{SiOH}$ terminated chemical oxide. But in SE and SPFM, a competitive oxidation and etching can be expected due to the presence of HF resulting in a controlled growth of the oxide layer (see Fig. 9). Competitive dissolution of wet-chemical oxide in SE and SPFM system takes place in two steps:

The first step is the dissolution of oxide by $\mathrm{HF}$ forming $\mathrm{SiF}_{6}{ }^{-}$ ions in the solution which involves fluoride absorption. Fluoride absorption (- $\mathrm{SiF}$ formation) occurs through the surface complexation reaction (known as inner sphere complexation process), shown in (a) to (b) formation of Fig. 12B. ${ }^{27}$ This Si-F bond induces polarization of underlying $\mathrm{Si}-\mathrm{O}$ bonds leading to the detachment of the surface silicon atom (c) of Fig. 12B with the attack of $\mathrm{H}_{2} \mathrm{O}$. The second step of $\mathrm{SiO}_{2}$ dissolution in $\mathrm{SE}$ and SPFM takes place by etching the last monolayer of $\mathrm{Si}^{2+}$ and resulting in $\mathrm{a} \mathrm{SiH}_{2}$ terminated surface. It is shown in (d) of Fig. 12B. $\mathrm{SiH}_{x}$ formation mainly occurs through adsorption of $\mathrm{H}$ at the surface dangling bond. The adsorbed fluoride passivation can be potentially removed and the final $\mathrm{SiH}_{2}$ surface structure can be obtained [(e) of Fig. 12B], when rinsed with DI water. $\mathrm{A} \mathrm{SiH}_{2}$ terminated surface is highly hydrophobic, as seen from contact angle values that are greater than $40^{\circ}$. During the treatment with SE and SPFM, there must be a competitive formation of wet-chemical oxide [(a) of Fig. 12] and its dissolution to result in a $\mathrm{SiH}_{x}$ terminated structure [(e) of Fig. 12]. This is supported by DRIFTS data at the $2000-2300 \mathrm{~cm}^{-1}$ region for $\mathrm{SiH}_{x}$ vibration in Fig. 6 and 7 and contact angle values. Though figures are not included here, higher values obtained for the area integral over $980-1300 \mathrm{~cm}^{-1}$ region of DRIFTS and higher values of thickness, obtained by ellipsometry for surfaces that were not pre-treated with $\mathrm{HF}$, can be attributed to the lack of the etching action of HF which removes $\mathrm{SiO}_{2}$ and controls the oxide growth.

\section{Conclusion}

Investigations were undertaken on $\mathrm{Si}(100)$ surfaces that were subjected to four different chemical treatments. Resultant surfaces were characterized by DRIFT spectral analysis, ellipsometry, contact angle analysis, and AFM techniques, as a function of reaction times to elucidate the time dependent evolution of surface properties. Omission of HF from the acid treatment mixtures resulted in surfaces with greater hydrophilic character with no detectable $\mathrm{SiH}_{x}$. These surfaces may be prone to organic and metallic contaminants accompanied by an oxide layer. While both $\mathrm{HNO}_{3}$ and $\mathrm{H}_{2} \mathrm{SO}_{4}-\mathrm{H}_{2} \mathrm{O}_{2}$ treatments for longer duration (30-60 min) yield a comparable number of hydroxyl groups, the thickness of the oxide layer was found to be higher for $\mathrm{HNO}_{3}$ treated surfaces. Surfaces, treated with $\mathrm{H}_{2} \mathrm{SO}_{4}-\mathrm{H}_{2} \mathrm{O}_{2}$, were sticky and contamination prone. We have studied in detail the impact of inclusion of HF in oxidizing acid mixtures. Inclusion of HF results in a mixed character, that contains both $\mathrm{SiH}_{x}$ and $\mathrm{SiOH}$ and the nature of which depends upon the reaction times. Longer incubation times yield a surface with predominant $\mathrm{SiH}_{x}$ coverage, whereas lower incubation times yield a surface with greater $\mathrm{SiOH}$ coverage.

For attaching biologically relevant molecules, silanization is an important step on hydroxylated silicon wafers (Fig. 1). Depending upon the final intended application of surfaces, a method can then be selected for surface modification with proper reaction time to get a hydrophilic surface with controlled oxide growth, free of contamination and with minimum surface roughness. To get a surface with higher silane grafting density, one may not need mixed termination of surface with $\mathrm{SiOH}$ and $\mathrm{SiH}_{X}$. In that case $\mathrm{HNO}_{3}$ treatment could be better over SPM, SE, and SPFM with a shorter reaction time, and dangerous acid mixture handling (SPM, SPFM, and SE) can be avoided.

\section{Acknowledgments}

This work was partially supported by NSF grant no. CTS0411632 and Army Research Laboratory grant no. W911NF-04-20011. We are grateful to the Center for Microelectronic and Optical Materials Research at University of Nebraska-Lincoln for providing us with the ellipsometer and AFM used in this study.

\section{References}

1. S. Sano, K. Kato, and Y. Ikada, Biomaterials, 14, 817 (1993).

2. F. Tao and G. Q. Xu, Acc. Chem. Res., 37, 882 (2004).

3. L. Buckberry and S. Bayliss, Mater. World, 7, 213 (1999).

4. H. F. Okorn-Schimdt, IBM J. Res. Dev., 43, 351 (1999).

5. R. K. Iler, The Chemistry of Silica, Wiley, New York (1979).

6. W. Stumm, Chemistry of Solid Water Interface, Wiley, New York (1992).

7. S. Flink, V. Vegel, C. J. M. Frank, and D. N. Reinhoudt, J. Phys. Org. Chem., 14, 407 (2001).

8. D. Graf, M. Grundner, and R. Schultz, J. Vac. Sci. Technol. A, 7, 808 (1989).

9. L. M. Loewenstein and P. W. Martens, J. Electrochem. Soc., 145, 2841 (1998).

10. K. Ljungberg, U. Jansson, S. Bengtsson, and A. Soderbarg, J. Electrochem. Soc., 143, 1709 (1996).

11. L. Xuegeng, H. Yuanqing, and M. T. Swihart, Langmuir, 20, 4720 (2004).

12. C. C. Shih, C. M. Shih, Y. Y. Su, R. A. Gerhardt, and S. J. Lin, J. Biomed. Mater. Res. A., 74, 325 (2005).

13. S. Verhaverbeke, R. Messoussi, and T. Ohmi, in Proceedings of the Second International Symposium on Ultraclean Processing of Silicon Surfaces (UCPSS'94), M. Heyns and P. Martens, Editors, p. 201, Leuven, Belgium (1994).

14. D. Graf, M. Grundner, and R. Schultz, J. Vac. Sci. Technol. A, 7, 808 (1989).

15. T. Takahagi, I. Nagai, A. Ishitani, H. Kuroda, and Y. Nagasawa, J. Appl. Phys., 64, 3516 (1988). 
16. L. Xuegeng, H. Yuanqing, S. S. Talukder, and M. T. Swihart, Langmuir, 19, 8490 (2003).

17. S. Verhaverbeke, I. Teerlinck, C. Vinckier, G. Stevens, R. Cartuyvels, and M. M. Heyns, J. Electrochem. Soc., 141, 2851 (1994).

18. H. Azour, J. Derouault, P. Lauroua, and G. Vezon, Spectrochim. Acta, Part A, 56, $1627(2000)$.

19. H. Bender, S. Verhaverbeke, and M. M. Heyns, J. Electrochem. Soc., 141, 3128 (1994).

20. T. W. Dijkstra, R. Duchateau, R. A. V. Santen, A. Meetsma, and G. P. A. Yap, J. Am. Chem. Soc., 124, 9856 (2002).
21. M. Grunder, J. Vac. Sci. Technol. A, 5, 2011 (1987).

22. Y. Nagasawa, I. Yoshii, K. Naruke, K. Yamamoto, H. Ishida, and A. Ishitani, $J$. Appl. Phys., 68, 1429 (1990).

23. W. A. Pliskin, J. Vac. Sci. Technol., 14, 1064 (1977).

24. C. J. Van Oss, Interfacial Forces in Aqueous Media, Dekker, New York (1969).

25. A. S. Dimitrov, P. A. Kralchevsky, A. D. Nikolov, H. Noshi, and M. Matsumosi, J. Colloid Interface Sci., 145, 279 (1991).

26. C. J. Van Oss, M. K. Chaudhury, and R. J. Good, Adv. Colloid Interface Sci., 28, 35 (1987).

27. K. Osseo-Asare, J. Electrochem. Soc., 143, 1339 (1996). 